\title{
Enumeration of Primary, Secondary, and Tertiary Monosubstituted Alkanes as Stereoisomers
}

\author{
Shinsaku FUJITA \\ Department of Chemistry and Materials Technology, Kyoto Institute of Technology \\ Matsugasaki, Sakyo-ku, Kyoto, 606-8585 Japan \\ e-mail: fujitas@chem.kit.ac.jp
}

(Received: September 26, 2006; Accepted for publication: December 5, 2006; Published on Web: March 2, 2007)

Monosubstituted alkanes are counted as stereoisomers by means of Fujita's proligand method (Fujita S (2005) Theor. Chem. Acc. 113:73-79, 113:80-86, Fujita S (2006) Theor. Chem. Acc. 115:37-53), where the numbers of primary, secondary, and tertiary ones are calculated after deriving respective functional equations. The procedures of counting are programmed by means of the Maple programming language. They are executed and the results collected up to carbon content 100 in a tabular form. By omitting the sphericities of the recursive functions $a(x), c\left(x^{2}\right)$, and $b(x)$ so as to give a single dummy variable $r(x)$, such functional equations with sphericity are transformed into Pólya's functional equations without sphericity, which are applied to the enumeration of primary, secondary, and tertiary monosubstituted alkanes as graphs (chemically, constitutional isomers). The results of Fujita's proligand method are compared with those based on Pólya's theorem in connection with several cases of pseudoasymmetry.

Keywords: Monosubstituted alkane, Primary, Secondary, Tertiary, Stereoisomer, Enumeration, Sphericity

\section{Introduction}

Henze and Blair [1] have obtained the numbers of aliphatic alcohols of given carbon contents, where the numbers were itemized with respect to their degrees of branching, i.e., primary, secondary, and tertiary alcohols. Their enumeration based on recursive equations was concerned with constitutional isomers (or mathematically graphs), but not with stereoisomers as three-dimensional (3D) objects.

The situation has not been restricted to such specific enumeration by Henze and Blair [1]. From the beginning when Cayley [2,3] started the combinatorial enumeration of monosubstituted alkanes (or mathematically rooted or planted trees), calculated numbers have been concerned with constitutional isomers (graphs), but not with stereoisomers (3D-objects) in most cases with or without such itemization due to the degrees of branching.

These situations have not been so dramatically changed even after the development of a more systematic method based on Pólya's theorem [4, 5], because stereoisomers were not treated properly. Thus, by using symmetric groups, enumeration results based on Pólya's theorem $[4,5]$ were concerned with graphs. By using alternating groups, on the other hand, achiral isomers, chiral isomers, and their enantiomers were counted independently, where pairwise recognition between a chiral isomer and its enantiomer was not been accomplished by Pólya's theorem. Moreover, Pólya's theorem did not take account of stereochemical problems on pseudoasymmetry and meso-compounds.

Among many contributions based on Pólya's theorem $[4,5]$ to chemistry [6-11], only Robinson et al. [12] to our best knowledge reported the enumeration of monosubstituted alkanes as stereoisomers by modifying Pólya's cycle indices (CIs). Even their treatment, however, did not take account of the classical stereochemical problems described above.

The disregard for pseudoasymmetry and mesocompounds has turned out to stem from the fact that both Pólya's theorem itself and its modification by Robinson et al. lack the concept of sphericity, which has been recently formulated by us $[13,14]$ in solving stereochemical problems and has been more recently modified so as to provide Fujita's proligand method [15-17]. Because the sphericity concept is a key to differentiate Fujita's proligand method from Pólya's theorem, it is important to exemplify how the sphericity concept works in various 
enumeration problems.

The sphericity concept has been developed as three versions, i.e., the concept "the sphericities of orbits" [13, 14], the concept "the sphericities of orbits based on cyclic groups" [18-20], and the concept "the sphericities of cycles" [15-17]. Among them, the concept "the sphericities of cycles" gave a basis of Fujita's proligand method [1517], which is here adopted as a principal tool for solving the enumeration problems described in the first paragraph of the Introduction.

Because the enumeration of monosubstituted alkanes (rooted or planted 3D-trees) as 3D-objects has been recently accomplished by using the proligand method [21], remaining problems are to obtain the numbers of primary, secondary, and tertiary aliphatic alcohols which are regarded as 3D-objects. The present paper is devoted to solving these problems, where their calculation procedures implemented by Maple programming language [22] are discussed in detail.

\section{Itemized Enumeration of Mono- substituted Alkanes}

\subsection{Recursive Functional Equations}

Let $a(x)$ be a generating function in which the coefficient $\left(\alpha_{k}\right)$ of the term $x^{k}$ represents the number of achiral monosubstituted alkanes (or planted 3D-trees) of carbon content $k$. Let $c\left(x^{2}\right)$ be a generating function in which the coefficient $\left(\gamma_{2 k}\right)$ of the term $x^{2 k}$ represents the number of achiral and chiral monosubstituted alkanes (or planted 3 D-trees) of carbon content $2 k$, where a diploid of enantiomers is counted just once [21]. Let $b(x)$ be a generating function in which the coefficient $\left(\beta_{k}\right)$ of the term $x^{k}$ represents the number of achiral and chiral monosubstituted alkanes (or planted 3D-trees) of carbon content $k$, where two enantiomers of each pair are separately counted. Thus, we can put the following ligand inventories:

$$
\begin{aligned}
a(x) & =\sum_{k=0}^{\infty} \alpha_{k} x^{k} \\
c\left(x^{2}\right) & =\sum_{k=0}^{\infty} \gamma_{2 k} x^{2 k} \\
b(x) & =\sum_{k=0}^{\infty} \beta_{k} x^{k},
\end{aligned}
$$

where $\alpha_{0}=1, \gamma_{0}=1$, and $\beta_{0}=1$ to treat trivial cases of terminal vertices (or hydrogen atoms).

A $\mathbf{C}_{3 v}$-skeleton for enumerating such monosubstituted alkanes is characterized by the right coset representation $\left(\mathbf{C}_{s} \backslash\right) \mathbf{C}_{3 v}$, i.e., $(1)(2)(3)$ for $I,\left(\begin{array}{lll}1 & 2 & 3\end{array}\right)$ for $C_{3}$, (1 32 ) for $C_{3}^{2}, \overline{(1)(23)}$ for $\sigma_{v(1)}, \overline{(13)(2)}$ for $\sigma_{v(2)}$, and $\overline{(12)(3)}$ for $\sigma_{v(3)}$, so that the resulting cycles are transformed into the corresponding products of sphericity in- dices, i.e., $b_{1}{ }^{3}$ for $I, b_{3}$ for two threefold rotations, and $a_{1} c_{2}$ for three reflections. The proligand method [1517] is applied to this case, where relevant cycle indices with chirality fittingness (CI-CFs) are obtained and transformed into eqs. $4-6$ by replacing $a_{d}$ by $a\left(x^{d}\right), c_{d}$ by $c\left(x^{d}\right)$, and $b_{d}$ by $b\left(x^{d}\right)$.

It follows that the three ligand inventories regarded as generating functions (eqs. 1 to 3 ) satisfy the following recursive functional equations:

$$
\begin{aligned}
a(x) & =1+x a(x) c\left(x^{2}\right) \\
c\left(x^{2}\right) & =1+\frac{x^{2}}{3}\left(c\left(x^{2}\right)^{3}+2 c\left(x^{6}\right)\right) \\
b(x) & =1+\frac{x}{3}\left(b(x)^{3}+2 b\left(x^{3}\right)\right) .
\end{aligned}
$$

Let $B(x)$ be a generating function for counting achiral and chiral planted promolecules, where each pair of enantiomers is counted just once. Let $C(x)$ be a generating function for counting chiral planted promolecules only, where each pair of enantiomers is counted just once. They are represented by the following equations:

$$
\begin{aligned}
& B(x)=\sum_{k=0}^{\infty} B_{k} x^{k} \\
& C(x)=\sum_{k=0}^{\infty} C_{k} x^{k},
\end{aligned}
$$

where we put $B_{0}=1$ and $C_{0}=0$ to treat a trivial case of carbon content 0 . Because we can place $B_{k}=\alpha_{k}+C_{k}$ and $\beta_{k}=\alpha_{k}+2 C_{k}$, eq. 4 (for $a(x)$ ) and eq. 6 (for $b(x)$ ) give the following equations:

$$
\begin{aligned}
B(x) & =\frac{1}{2}(a(x)+b(x)) \\
C(x) & =\frac{1}{2}(b(x)-a(x)) .
\end{aligned}
$$

\subsection{Primary Monosubstituted Alkanes}

Primary monosubstituted alkanes can be derived by placing an appropriate ligand on the vertex 1 of the $\mathbf{C}_{s^{-}}$ skeleton (1). The action of symmetry operations is shown in Figure 1. The transitivity of the vertex 1 is characterized by a trivial right coset representation $\left(\mathbf{C}_{s} \backslash\right) \mathbf{C}_{s}=$ $\{(1), \overline{(1)}\}$, where the cycle (1) is hemispheric and the cycle $\overline{(1)}\}$ is homospheric.

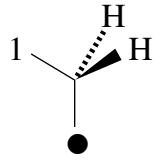

1a, $I$

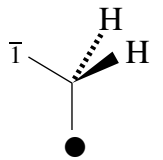

$\mathbf{1 b}, \sigma_{v(1)}$

$$
\overline{(1)}, a_{1}
$$

Figure 1. Symmetry operations of the $\mathbf{C}_{s}$-skeleton for counting primary monosubstituted alkanes (1). 
We can apply Theorem 2 of [17] to the enumeration of primary monosubstituted alkanes without any modification. Hence, by using the product of SIs collected in Figure 1, the cycle index with chirality fittingness (CI$\mathrm{CF}$ ) for this case is calculated as follows:

$$
\mathrm{CI}-\mathrm{CF}\left(\mathbf{C}_{s} ; a_{d}, b_{d}\right)=\frac{1}{2}\left(b_{1}+a_{1}\right),
$$

which counts achiral primary monosubstituted alkanes and enantiomeric pairs of chiral ones. Theorem 3 of [17] for the enumeration of ligands under the action of the maximum chiral subgroup is applied to this case so as to derive the following $\mathrm{CI}-\mathrm{CF}$ :

$$
\mathrm{CI}-\mathrm{CF}\left(\mathbf{C}_{1} ; b_{d}\right)=b_{1},
$$

which counts achiral primary monosubstituted alkanes and chiral ones, where two enantiomers of each pair are counted separately. We apply the first proposition of Theorem 4 for the enumeration of achiral ligands [17] to this case so as to derive the following $\mathrm{CI}-\mathrm{CF}_{A}$ :

$$
\begin{aligned}
& \mathrm{CI}-\mathrm{CF}_{A}\left(\mathbf{C}_{s} ; a_{d}, b_{d}\right) \\
& \quad=2 \mathrm{CI}-\mathrm{CF}\left(\mathbf{C}_{s} ; a_{d}, b_{d}\right)-\mathrm{CI}-\mathrm{CF}\left(\mathbf{C}_{1} ; b_{d}\right) \\
& \quad=a_{1}
\end{aligned}
$$

which counts achiral primary monosubstituted alkanes only. We use the second proposition of Theorem 4 for the enumeration of chiral ligands [17] to obtain the following $\mathrm{CI}-\mathrm{CF}_{C}$ :

$$
\begin{aligned}
& \mathrm{CI}^{-\mathrm{CF}_{C}}\left(\mathbf{C}_{s} ; a_{d}, b_{d}\right) \\
& \quad=\mathrm{CI}-\mathrm{CF}\left(\mathbf{C}_{1} ; b_{d}\right)-\mathrm{CI}-\mathrm{CF}\left(\mathbf{C}_{s} ; a_{d}, b_{d}\right) \\
& =\frac{1}{2}\left(b_{1}-a_{1}\right)
\end{aligned}
$$

which counts enantiomeric pairs of chiral primary monosubstituted alkanes only, where each pair of enantiomers is counted just once.

Let $P_{k}, P_{k}{ }^{(A)}$, and $P_{k}{ }^{(C)}$ be the number of achiral primary monosubstituted alkanes plus enantiomeric pairs, the number of achiral ones, and the number of enantiomeric pairs. They are represented as the following generating functions:

$$
\begin{aligned}
P(x) & =\sum_{k=1}^{\infty} P_{k} x^{k} \\
P(x)^{(A)} & =\sum_{k=1}^{\infty} P_{k}^{(A)} x^{k} \\
P(x)^{(C)} & =\sum_{k=1}^{\infty} P_{k}^{(C)} x^{k},
\end{aligned}
$$

where $x^{k}$ corresponds to the carbon content $k \geq 1$.

By starting from eq. 11 , the SIs $b_{1}$ and $a_{1}$ are replaced by $b(x)$ and $a(x)$ respectively. Thereby, we obtain the following functional equation by multiplying by $x$ for the principal vertex:

$$
P(x)=\frac{x}{2}(b(x)+a(x)) .
$$

It should be noted that the first term 1 in $b(x)$ (eq. 6) or $a(x)$ (eq. 4 ) is not omitted because a monosubstituted methane $\left(\bullet-\mathrm{CH}_{3}\right)$ should be counted as a trivial case in addition to usual primary monosubstituted alkanes. On a similar line, eq. 13 gives the following functional equation:

$$
P(x)^{(A)}=x a(x)
$$

after multiplied by $x$ to take account of the principal vertex. Further, eq. 14 gives the following functional equation:

$$
P(x)^{(C)}=\frac{x}{2}(b(x)-a(x))
$$

after multiplied by $x$.

Because $a(x)$ (by eq. 4$), c\left(x^{2}\right)$ (by eq. 5), and $b(x)$ (by eq. 6) have been evaluated recursively, we are able to obtain the coefficients $P_{k}$ (eq. 15), $P_{k}^{(A)}$ (eq. 16), and $P_{k}{ }^{(C)}$ (eq. 17) by expanding eqs. 18, 19, and 20. Procedures for calculating them were programmed by using Maple programming language as follows.

Maple program for enumeration primary monosubstituted alkanes, "P1-100.mpl":

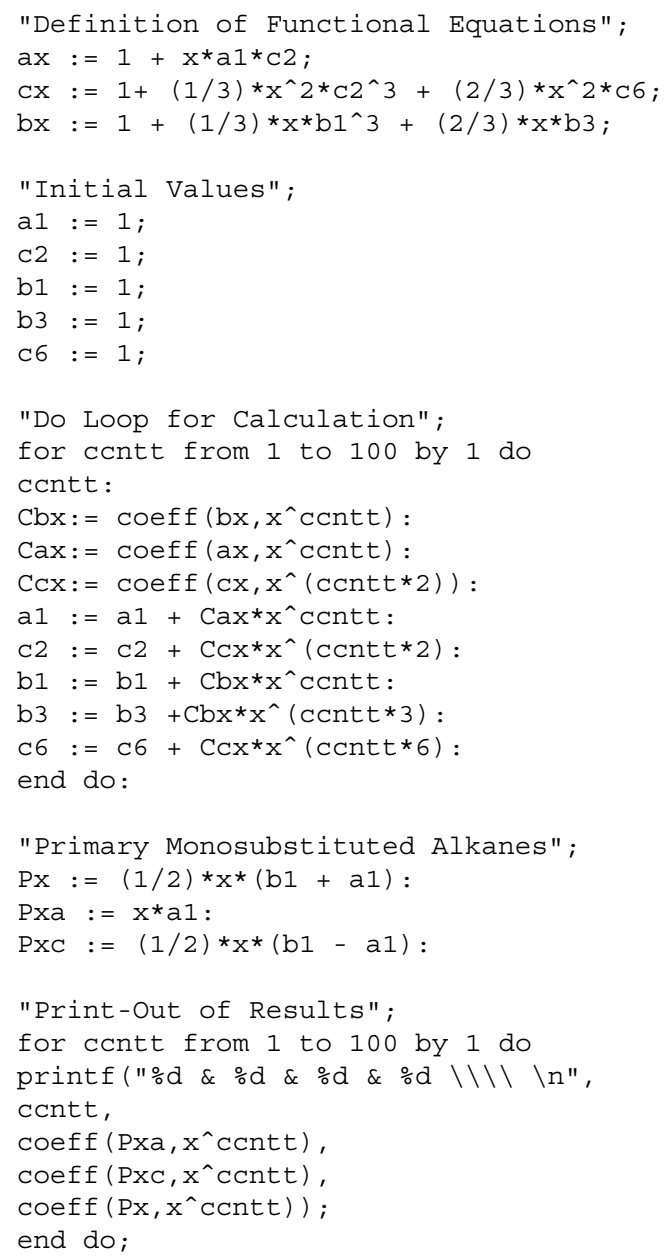


Table 1. Numbers of Primary Monosubstituted Alkanes as Stereoisomers ${ }^{\mathrm{a}}$

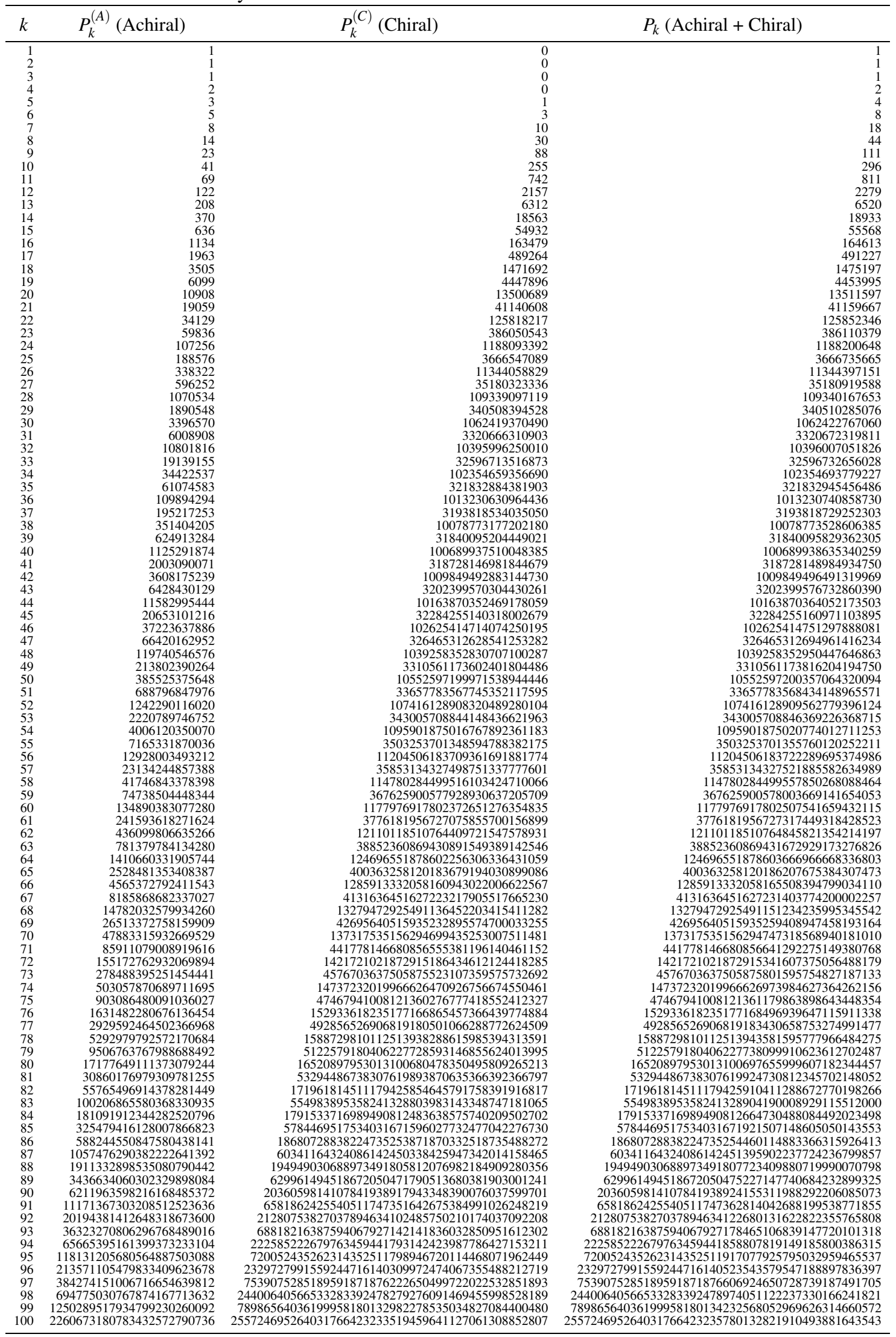

${ }^{a}$ In each value of $P_{k}{ }^{(C)}$ (Chiral) or $P_{k}$ (Chiral + Achiral), each enantiomeric pair is counted just once for chiral primary monosubstituted alkanes. 
In this code, the abbreviated symbols for functional equations are used as follows: a 1 for $a(x)$, c2 for $c\left(x^{2}\right)$, c6 for $c\left(x^{6}\right)$, and so on. The first paragraph ("Definition of Functional Equations") declares three functional equations (eqs. 4-6). In the 2nd paragraph ("Initial Values"), the initial values for the initial (trivial) planted promolecule are set as $\alpha_{0}=1, \gamma_{0}=1$, and $\beta_{0}=1$ by encoding a1 $:=1 ; \mathrm{c} 2:=1$; and so on. The 3rd paragraph ("Do Loop for Calculation") shows a do loop for calculating $\alpha_{k}, \gamma_{k}$, and $\beta_{k}$ recursively by using a Maple command coeff. After escaping from the do loop, the 4th paragraph ("Primary Monosubstituted Alkanes") declares the calculation of $P(x)$ (eq. 18), $P(x)^{(A)}$ (eq. 19), and $P(x)^{(C)}$ (eq. 20). The 5th paragraph (the final do loop named "Print-Out of Results") shows the print-out of the calculation results.

The code was stored in a file named "P1-100.mpl"and then executed by inputting the following command on the Maple inputting window:

read "P1-100.mpl";

Thereby, we obtained the coefficients $P_{k}$ (eq. 15) for $P(x)$ (eq. 18), $P_{k}^{(A)}$ (eq. 16) for $P(x)^{(A)}$ (eq. 19), and $P_{k}{ }^{(C)}$ (eq. 17) for $P(x)^{(C)}$ (eq. 20), as collected in Table 1. It should be noted that each enantiomeric pair is counted just once throughout the present enumeration. Hence, the value of $P_{k}{ }^{(C)}$ is the number concerned with pairs of enantiomeric primary monosubstituted alkanes. On the same line, the value of $P_{k}$ is the number concerned with achiral primary monosubstituted alkanes plus pairs of enantiomeric primary monosubstituted alkanes.

\subsection{Secondary Monosubstituted Alkanes}

Secondary monosubstituted alkanes are derived by placing two appropriate ligands on the vertices 2 and 3 of the $\mathbf{C}_{s}$-skeleton (2). The action of symmetry operations is shown in Figure 2. The transitivity of the vertices 2 and 3 is characterized by a right coset representation $\left(\mathbf{C}_{1} \backslash\right) \mathbf{C}_{s}$ $=\{(2)(3), \overline{(23)}\}$, where the one-cycle (2) or (3) is hemispheric so as to take an SI $b_{1}$, while the two-cycle $\overline{(23)}$ is enantiospheric so as to take an SI $c_{2}$.

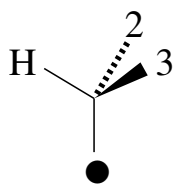

$$
\begin{array}{cc}
\mathbf{2 a}, I & \mathbf{2 b}, \sigma_{v(1)} \\
(2)(3), b_{1}^{2} & \overline{(23)}, c_{2}
\end{array}
$$

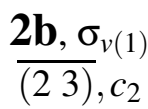

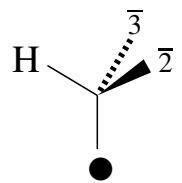

Figure 2. Symmetry operations of the $\mathbf{C}_{s}$-skeleton for counting secondary monosubstituted alkanes (2).
We apply Theorem 2 of [17] to the enumeration of secondary monosubstituted alkanes, so that we calculate the CI-CF for this case (Figure 2) as follows:

$$
\mathrm{CI}-\mathrm{CF}\left(\mathbf{C}_{s} ; a_{d}, b_{d}\right)=\frac{1}{2}\left(b_{1}^{2}+c_{2}\right),
$$

which counts achiral secondary monosubstituted alkanes and enantiomeric pairs of chiral ones. According to Theorem 3 of [17] for the enumeration of ligands under the action of the maximum chiral subgroup, we derive the following $\mathrm{CI}-\mathrm{CF}$ in order to count achiral secondary monosubstituted alkanes and chiral ones:

$$
\mathrm{CI}-\mathrm{CF}\left(\mathbf{C}_{1} ; b_{d}\right)=b_{1}^{2},
$$

where two enantiomers of each pair are counted separately. We apply the first proposition of Theorem 4 for the enumeration of achiral ligands [17] to this case so as to derive the following $\mathrm{CI}-\mathrm{CF}_{A}$ :

$$
\begin{aligned}
& \mathrm{CI}^{-\mathrm{CF}_{A}}\left(\mathbf{C}_{s} ; a_{d}, b_{d}\right) \\
& \quad=2 \mathrm{CI}-\mathrm{CF}\left(\mathbf{C}_{s} ; a_{d}, b_{d}\right)-\mathrm{CI}-\mathrm{CF}\left(\mathbf{C}_{1} ; b_{d}\right) \\
& =c_{2}
\end{aligned}
$$

which counts achiral secondary monosubstituted alkanes only. We adopt the second proposition of Theorem 4 for the enumeration of chiral ligands [17] to obtain the following $\mathrm{CI}-\mathrm{CF}_{C}$ :

$$
\begin{aligned}
& \text { CI-CF }{ }_{C}\left(\mathbf{C}_{s} ; a_{d}, b_{d}\right) \\
& \quad=\operatorname{CI}-\mathrm{CF}\left(\mathbf{C}_{1} ; b_{d}\right)-\mathrm{CI}-\mathrm{CF}\left(\mathbf{C}_{s} ; a_{d}, b_{d}\right) \\
& =\frac{1}{2}\left(b_{1}^{2}-c_{2}\right)
\end{aligned}
$$

which counts enantiomeric pairs of chiral secondary monosubstituted alkanes only, where each pair of enantiomers is counted just once.

Let $S_{k}, S_{k}{ }^{(A)}$, and $S_{k}{ }^{(C)}$ be the number of achiral secondary monosubstituted alkanes plus enantiomeric pairs, the number of achiral ones, and the number of enantiomeric pairs. Then, we obtain the corresponding generating functions as follows:

$$
\begin{aligned}
S(x) & =\sum_{k=1}^{\infty} S_{k} x^{k} \\
S(x)^{(A)} & =\sum_{k=1}^{\infty} S_{k}^{(A)} x^{k} \\
S(x)^{(C)} & =\sum_{k=1}^{\infty} S_{k}^{(C)} x^{k},
\end{aligned}
$$

where $x^{k}$ corresponds to the carbon content $k \geq 1$.

To evaluate the generating function $S(x)$ (eq. 25), we replace the SIs $b_{1}$ and $c_{2}$ in eq. 21 by $b(x)-1$ and $c\left(x^{2}\right)$ -1 , respectively. The resulting equation is multiplied by $x$ for the principal vertex to give the following functional equation: 
Table 2. Numbers of Secondary Monosubstituted Alkanes as Stereoisomers ${ }^{\text {a }}$

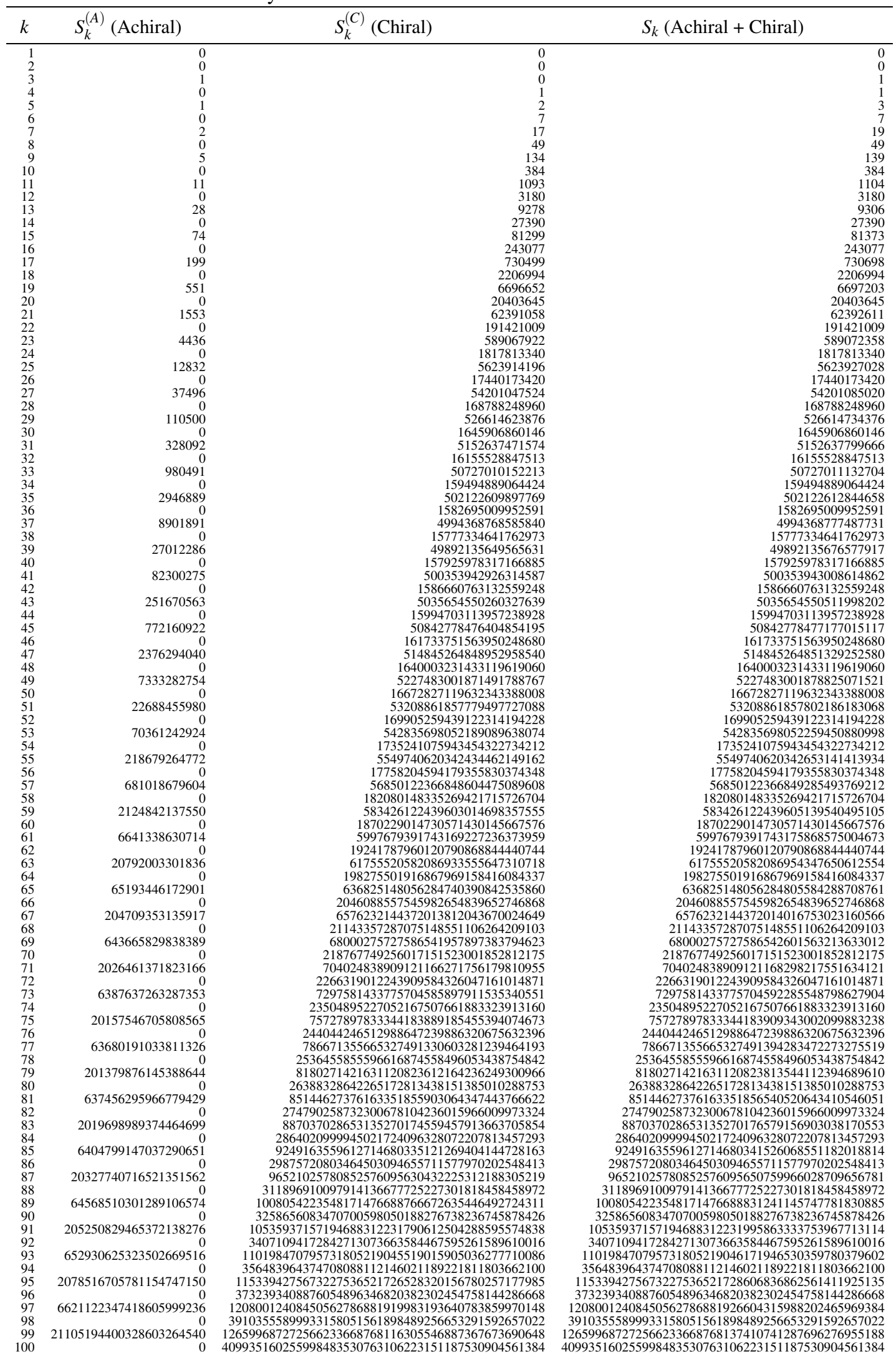

${ }^{a}$ In each value of $S_{k}{ }^{(C)}$ (Chiral) or $S_{k}$ (Chiral + Achiral), each enantiomeric pair is counted just once for chiral secondary monosubstituted alkanes. 


$$
S(x)=\frac{x}{2}\left((b(x)-1)^{2}+\left(c\left(x^{2}\right)-1\right)\right) .
$$

It should be noted that the first term 1 in $b(x)$ or $c\left(x^{2}\right)$ is omitted; otherwise, a monosubstituted methane $\left(\bullet-\mathrm{CH}_{3}\right)$ and primary monosubstituted alkanes (e.g., $\bullet-\mathrm{CH}_{2}-\mathrm{R}$ ) would be erroneously counted in.

On a similar line, eq. 23 when modified and multiplied by $x$ gives the following functional equation:

$$
S(x)^{(A)}=x\left(c\left(x^{2}\right)-1\right) .
$$

Further, the modification of eq. 24 and the subsequent multiplication by $x$ give the following functional equation:

$$
S(x)^{(C)}=\frac{x}{2}\left((b(x)-1)^{2}-\left(c\left(x^{2}\right)-1\right)\right) .
$$

Procedures for calculating $S_{k}$ (eq. 25) by $S(x)$ (eq. 28), $S_{k}{ }^{(A)}$ (eq. 26) by $S(x)^{(A)}$ (eq. 29), and $S_{k}^{(C)}$ (eq. 27) by $S(x)^{(C)}$ (eq. 30) were programmed by using Maple programming language as follows (the omitted paragraphs are the same as those of "P1-100.mpl").

Maple program for enumeration primary monosubstituted alkanes: "S1-100.mpl":

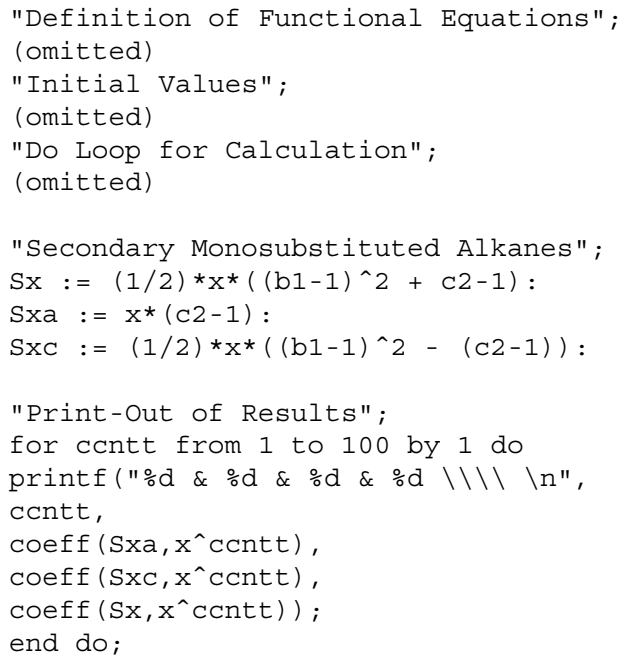

The execution of the program gave the results collected in Table 2.

\subsection{Tertiary Monosubstituted Alkanes}

Tertiary monosubstituted alkanes are derived from the same skeleton (3) as discussed for monosubstituted alkanes without itemization due to branching (Figure 3). A different point is that all of the three substituents in a tertiary monosubstituted alkane must be alkyl ligands, but not hydrogens.
We apply Theorem 2 , Theorem 3 , and the two propositions of Theorem 4 of [17] to the enumeration of tertiary monosubstituted alkanes. To count achiral planted promolecules and enantiomeric pairs of chiral planted promolecules, we employ the following CI-CF:

$$
\mathrm{CI}-\mathrm{CF}\left(\mathbf{C}_{3 v} ; a_{d}, c_{d}, b_{d}\right)=\frac{1}{6}\left(b_{1}^{3}+2 b_{3}+3 a_{1} c_{2}\right) .
$$

We use the following CI-CF:

$$
\mathrm{CI}-\mathrm{CF}\left(\mathbf{C}_{3} ; b_{d}\right)=\frac{1}{3}\left(b_{1}^{3}+2 b_{3}\right)
$$

in order to count achiral and chiral planted promolecules. For the purpose of counting achiral planted promolecules only, we start from the following $\mathrm{CI}-\mathrm{CF}_{A}$ :

$$
\begin{aligned}
& \mathrm{CI}^{-\mathrm{CF}_{A}}\left(\mathbf{C}_{3 v} ; a_{d}, c_{d}, b_{d}\right) \\
& \quad=2 \mathrm{CI}-\mathrm{CF}\left(\mathbf{C}_{3 v} ; a_{d}, c_{d}, b_{d}\right)-\mathrm{CI}-\mathrm{CF}\left(\mathbf{C}_{3} ; b_{d}\right) \\
& \quad=a_{1} c_{2} .
\end{aligned}
$$

To count chiral planted promolecules only, we use the following $\mathrm{CI}-\mathrm{CF}_{C}$ :

$$
\begin{aligned}
& \mathrm{CI}^{\mathrm{C}-\mathrm{CF}_{C}}\left(\mathbf{C}_{3 v} ; a_{d}, c_{d}, b_{d}\right) \\
& \quad=\mathrm{CI}-\mathrm{CF}\left(\mathbf{C}_{3} ; b_{d}\right)-\mathrm{CI}-\mathrm{CF}\left(\mathbf{C}_{3 v} ; a_{d}, c_{d}, b_{d}\right) \\
& \quad=\frac{1}{6}\left(b_{1}^{3}+2 b_{3}-3 a_{1} c_{2}\right) .
\end{aligned}
$$

We have already used these equations to obtain the functional equations for recursive calculations, i.e., $a(x)$ (eq. 4), $c\left(x^{2}\right)$ (eq. 5), and $b(x)$ (eq. 6). But, we here use them in a slightly different manner in order to treat tertiary monosubstituted alkanes.

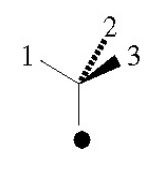

3a,

(1)(2)(3), $b_{1}^{3}$

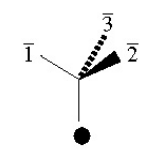

3d, $\sigma_{v(1)}$ $\overline{(1)(23)}, a_{1} c_{2}$

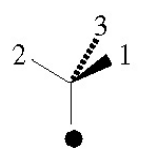

$\mathbf{3 b}, C_{3}$

(1 23$), b_{3}$

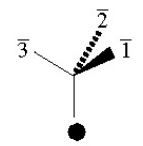

$\mathbf{3 e}, \boldsymbol{\sigma}_{v(2)}$

$\overline{(13)(2)}, a_{1} c_{2}$

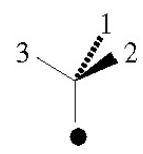

3c, $C_{3}^{2}$

(132), $b_{3}$

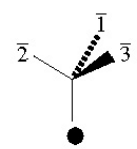

3f, $\sigma_{v(3)}$
Figure 3. Symmetry operations for a $\mathbf{C}_{3 v}$-skeleton (3). The identity operation $(I)$ converts $\mathbf{3}$ into itself, where the resulting skeleton is denoted as $\mathbf{3 a}$. 
Table 3. Numbers of Tertiary Monosubstituted Alkanes as Stereoisomers ${ }^{\mathrm{a}}$

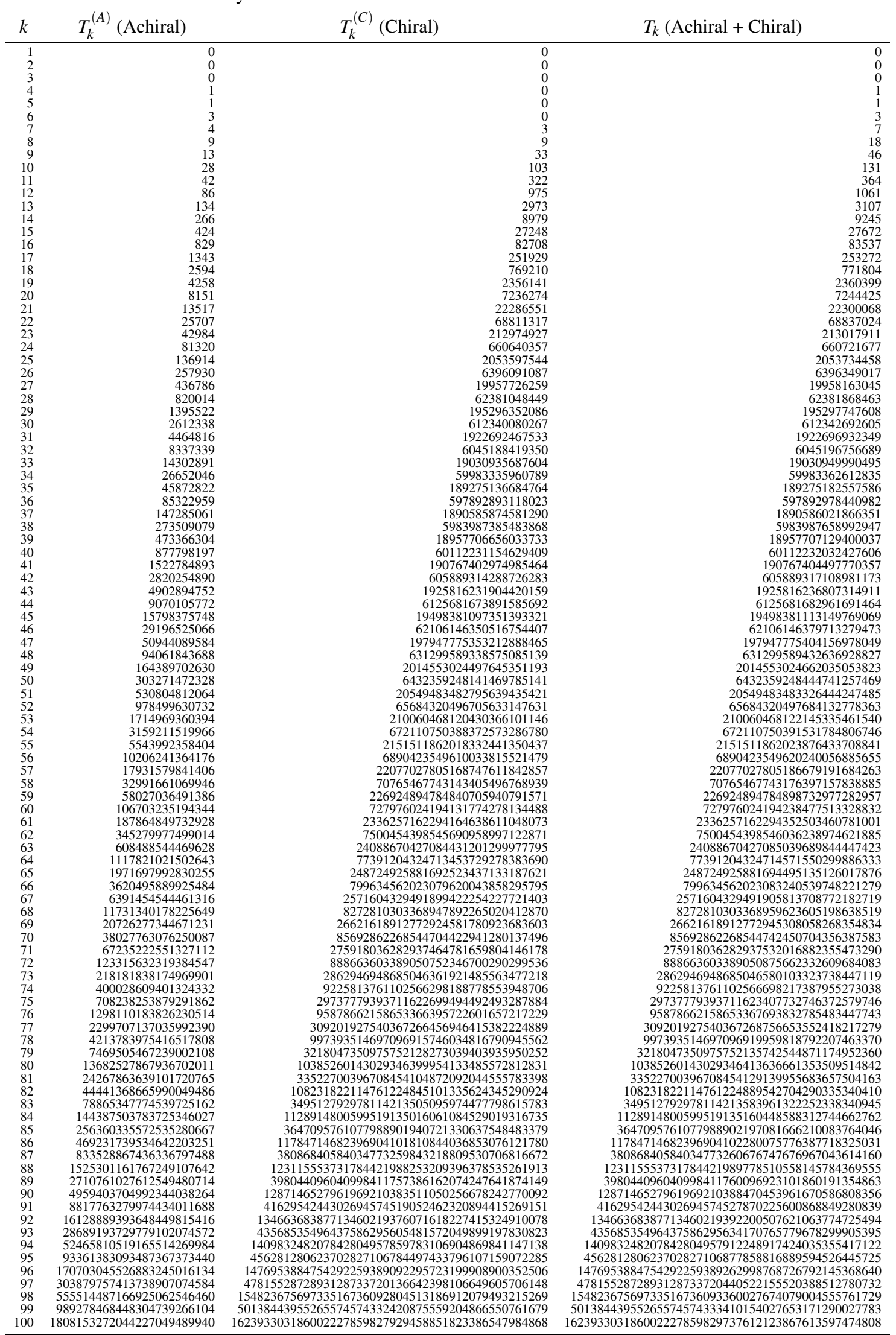

${ }^{\mathrm{a}}$ In each value of $T_{k}{ }^{(C)}$ (Chiral) or $T_{k}$ (Chiral + Achiral), each enantiomeric pair is counted just once for chiral tertiary monosubstituted alkanes. 
Let $T_{k}, T_{k}{ }^{(\mathrm{A})}$, and $T_{k}{ }^{(\mathrm{C})}$ be the number of achiral tertiary monosubstituted alkanes plus enantiomeric pairs, the number of achiral ones, and the number of enantiomeric pairs. They satisfy the following generating functions:

$$
\begin{aligned}
T(x) & =\sum_{k=1}^{\infty} T_{k} x^{k} \\
T(x)^{(A)} & =\sum_{k=1}^{\infty} T_{k}^{(A)} x^{k} \\
T(x)^{(C)} & =\sum_{k=1}^{\infty} T_{k}^{(C)} x^{k},
\end{aligned}
$$

where $x^{k}$ corresponds to the carbon content $k \geq 1$.

The SIs $a_{d}, c_{d}$, and $b_{d}$ in eq. 31 are replaced by $a\left(x^{d}\right)$ $1, c\left(x^{d}\right)-1$ and $b\left(x^{d}\right)-1$ respectively. The resulting equation is multiplied by $x$ to take the principal vertex into consideration. Thereby, we obtain the following functional equation:

$$
\begin{aligned}
T(x)= & \frac{x}{6}\left((b(x)-1)^{3}+2(b(x)-1)\right. \\
& \left.+3(a(x)-1)\left(c\left(x^{2}\right)-1\right)\right) .
\end{aligned}
$$

It should be noted that the first term 1 in $b(x), a(x)$, or $c\left(x^{2}\right)$ is omitted in order to exclude monosubstituted methane $\left(\bullet-\mathrm{CH}_{3}\right)$, primary (e.g., $\left.\bullet-\mathrm{CH}_{2}-\mathrm{R}\right)$, and secondary monosubstituted alkanes (e.g., •- $\mathrm{CH}-\mathrm{RR}$ '). On a similar line, eq. 33 gives the following functional equation:

$$
T(x)^{(A)}=x(a(x)-1)\left(c\left(x^{2}\right)-1\right) .
$$

Further, eq. 34 gives the following functional equation:

$$
\begin{aligned}
T(x)^{(C)}= & \frac{x}{6}\left((b(x)-1)^{3}+2(b(x)-1)\right. \\
& \left.-3(a(x)-1)\left(c\left(x^{2}\right)-1\right)\right) .
\end{aligned}
$$

Procedures for calculating $T_{k}$ (eq. 35) by $T(x)$ (eq. 38), $T_{k}^{(A)}$ (eq. 36) by $T(x)^{(A)}$ (eq. 39), and $T_{k}{ }^{(C)}$ (eq. 37) by $T(x)^{(C)}$ (eq. 40) were programmed by using the Maple programming language as follows (the omitted paragraphs are the same as those of "P1-100.mpl").

Maple program for enumeration primary monosubstituted alkanes: "T1-100.mpl":

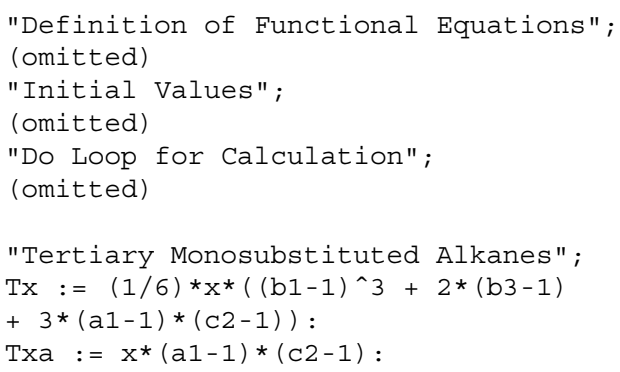

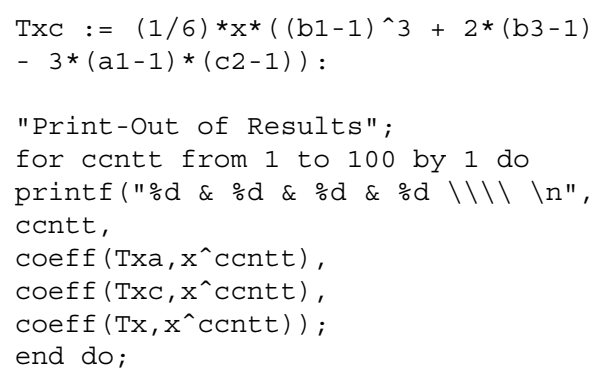

The execution of the program gave the results collected in Table 3.

\subsection{Total Numbers}

The total numbers of achiral stereoisomers of primary, secondary, and tertiary monosubstituted alkanes are calculated by adding the coefficients of the term $x^{k}$ appearing in eqs. 19, 29, and 39. The results should be identical with the values $\alpha_{k}$ alternatively calculated by using eq. 4 . In fact, we can obtain the following relationship:

$$
P(x)^{(A)}+S(x)^{(A)}+T(x)^{(A)}=x a(x) c\left(x^{2}\right),
$$

where the coefficient of each term is identical with that of eq. 4 except $x^{0}$.

The total numbers of achiral enantiomeric pairs of primary, secondary, and tertiary monosubstituted alkanes are calculated by adding the coefficients of the term $x^{k}$ appearing in eqs. 20,30, and 40. The results should be identical with the values $C_{k}$ alternatively calculated by using $C(x)$ (eq. 10). In fact, we can obtain the following relationship:

$$
\begin{aligned}
& P(x)^{(C)}+S(x)^{(C)}+T(x)^{(C)} \\
& \quad=\frac{x}{6}\left(b(x)^{3}+2 b\left(x^{3}\right)-3 a(x) c\left(x^{2}\right)\right),
\end{aligned}
$$

which is identical with the expanded equation derived from $C(x)$ (eq. 10).

The total numbers of achiral plus enantiomeric pairs of primary, secondary, and tertiary monosubstituted alkanes are calculated by adding the coefficients of the term $x^{k}$ appearing in eqs. 18, 28, and 38. The results should be identical with the values $B_{k}$ alternatively obtained by $B(x)$ (eq. 9). In fact, we can obtain

$$
\begin{aligned}
& P(x)+S(x)+T(x) \\
& \quad=\frac{x}{6}\left(b(x)^{3}+2 b\left(x^{3}\right)+3 a(x) c\left(x^{2}\right)\right),
\end{aligned}
$$

which is identical with the expanded equation derived from $B(x)$ (eq. 9) except the term $x^{0}$.

We are able to verify these facts numerically by the following Maple program "Test1-100.mpl", where we put: $A$ A for eq. $41, \mathrm{CC}$ for eq. $42, \mathrm{BB}$ for eq. $43, \mathrm{BBx}$ for eq. $9, \mathrm{CCx}$ for eq. 10 . 
Maple program for enumeration monosubstituted alkanes: "Test1-100.mpl":

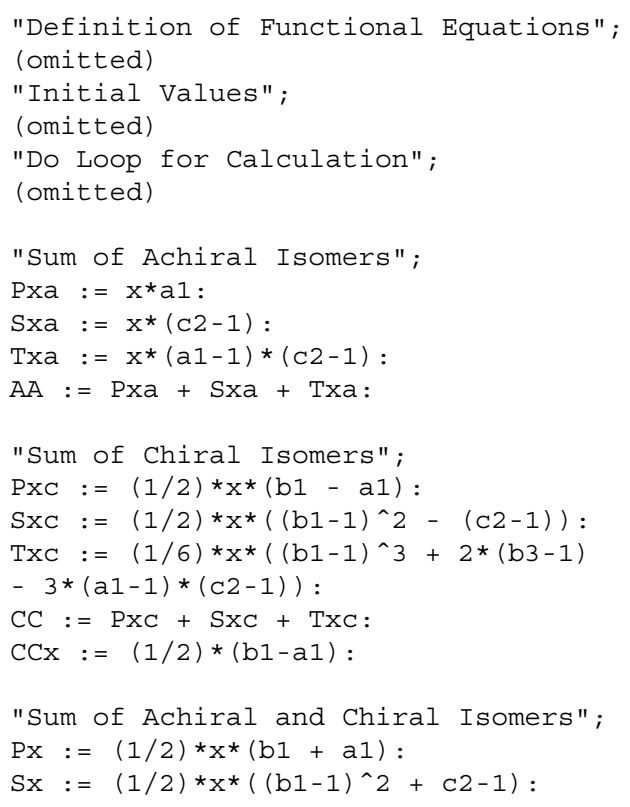

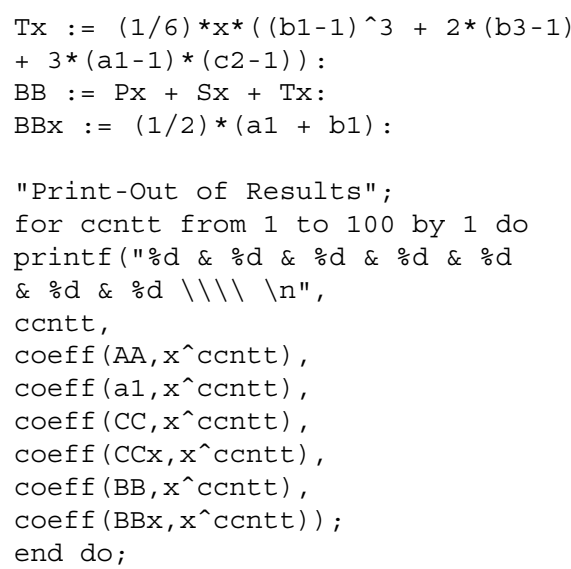

The results are summarized in Table 4, where the coefficients appearing in $\mathrm{AA}, \mathrm{CC}$, and $\mathrm{BB}$ are listed in the $B_{k}{ }^{(A)}$ '-, $B_{k}{ }^{(C)}$ '-, and $B_{k}$ '-columns, respectively. For comparison, Table 4 also collects the values of $\alpha_{k}$ (eq. 4 ), $C_{k}$ (eq. 10), and $B_{k}$ (eq. 9). Obviously, we can find equality between $B_{k}{ }^{(A)}$, and $\alpha_{k}$, between $B_{k}{ }^{(C)}$, and $C_{k}$, as well as between $B_{k}$ ' and $B_{k}$.

Table 4. Total Numbers of Monosubstituted Alkanes as Stereoisomers ${ }^{\mathrm{a}}$

\begin{tabular}{|c|c|c|c|c|c|c|}
\hline \multirow[b]{2}{*}{$k$} & \multicolumn{2}{|c|}{ Achiral } & \multicolumn{2}{|c|}{ Chiral } & \multicolumn{2}{|c|}{ Achiral + Chiral } \\
\hline & $B_{k}^{(A) \prime}$ & $\alpha_{k}$ & $B_{k}^{(C) \prime}$ & $C_{k}$ & $B_{k}^{\prime}$ & $B_{k}$ \\
\hline 1 & 1 & 1 & 0 & 0 & 1 & 1 \\
\hline 2 & 1 & 1 & 0 & 0 & 1 & 1 \\
\hline 3 & 2 & 2 & 0 & 0 & 2 & 2 \\
\hline 4 & 3 & 3 & 1 & 1 & 4 & 4 \\
\hline 5 & 5 & 5 & 3 & 3 & 8 & 8 \\
\hline 6 & 8 & 8 & 10 & 10 & 18 & 18 \\
\hline 7 & 14 & 14 & 30 & 30 & 44 & 44 \\
\hline 8 & 23 & 23 & 88 & 88 & 111 & 111 \\
\hline 9 & 41 & 41 & 255 & 255 & 296 & 296 \\
\hline 10 & 69 & 69 & 742 & 742 & 811 & 811 \\
\hline 11 & 122 & 122 & 2157 & 2157 & 2279 & 2279 \\
\hline 12 & 208 & 208 & 6312 & 6312 & 6520 & 6520 \\
\hline 13 & 370 & 370 & 18563 & 18563 & 18933 & 18933 \\
\hline 14 & 636 & 636 & 54932 & 54932 & 55568 & 55568 \\
\hline 15 & 1134 & 1134 & 163479 & 163479 & 164613 & 164613 \\
\hline 16 & 1963 & 1963 & 489264 & 489264 & 491227 & 491227 \\
\hline 17 & 3505 & 3505 & 1471692 & 1471692 & 1475197 & 1475197 \\
\hline 18 & 6099 & 6099 & 4447896 & 4447896 & 4453995 & 4453995 \\
\hline $\begin{array}{l}19 \\
19\end{array}$ & 10908 & 10908 & 13500689 & 13500689 & 13511597 & 13511597 \\
\hline 20 & 19059 & 19059 & 41140608 & 41140608 & 41159667 & 41159667 \\
\hline 21 & 34129 & 34129 & 125818217 & 125818217 & 125852346 & 125852346 \\
\hline 22 & 59836 & 59836 & 386050543 & 386050543 & 386110379 & 386110379 \\
\hline 23 & 107256 & 107256 & 1188093392 & 1188093392 & 1188200648 & 1188200648 \\
\hline 24 & 188576 & 188576 & 3666547089 & 3666547089 & 3666735665 & 3666735665 \\
\hline 25 & 338322 & 338322 & 11344058829 & 11344058829 & 11344397151 & 11344397151 \\
\hline 26 & 596252 & 596252 & 35180323336 & 35180323336 & 35180919588 & 35180919588 \\
\hline 27 & 1070534 & 1070534 & 109339097119 & 109339097119 & 109340167653 & 109340167653 \\
\hline 28 & 1890548 & 1890548 & 340508394528 & 340508394528 & 340510285076 & 340510285076 \\
\hline 29 & 3396570 & 3396570 & 1062419370490 & 1062419370490 & 1062422767060 & 1062422767060 \\
\hline 30 & 6008908 & 6008908 & 3320666310903 & 3320666310903 & 3320672319811 & 3320672319811 \\
\hline 31 & 10801816 & 10801816 & 10395996250010 & 10395996250010 & 10396007051826 & 10396007051826 \\
\hline 32 & 19139155 & 19139155 & 32596713516873 & 32596713516873 & 32596732656028 & 32596732656028 \\
\hline 33 & 34422537 & 34422537 & 102354659356690 & 102354659356690 & 102354693779227 & 102354693779227 \\
\hline 34 & 61074583 & 61074583 & 321832884381903 & 321832884381903 & 321832945456486 & 321832945456486 \\
\hline 35 & 109894294 & 109894294 & 1013230630964436 & 1013230630964436 & 1013230740858730 & 1013230740858730 \\
\hline 36 & 195217253 & 195217253 & 3193818534035050 & 3193818534035050 & 3193818729252303 & 3193818729252303 \\
\hline 37 & 351404205 & 351404205 & 10078773177202180 & 10078773177202180 & 10078773528606385 & 10078773528606385 \\
\hline 38 & 624913284 & 624913284 & 31840095204449021 & 31840095204449021 & 31840095829362305 & 31840095829362305 \\
\hline 39 & 1125291874 & 1125291874 & 100689937510048385 & 100689937510048385 & 1006899386353440259 & 100689938635340259 \\
\hline 40 & 2003090071 & 2003090071 & 318728146981844679 & 318728146981844679 & 318728148984934750 & 318728148984934750 \\
\hline 41 & 3608175239 & 3608175239 & 1009849492883144730 & 1009849492883144730 & 1009849496491319969 & 1009849496491319969 \\
\hline 42 & 6428430129 & 6428430129 & 3202399570304430261 & 3202399570304430261 & 3202399576732860390 & 3202399576732860390 \\
\hline 43 & 11582995444 & 11582995444 & 10163870352469178059 & 10163870352469178059 & 10163870364052173503 & 10163870364052173503 \\
\hline 44 & 20653101216 & 20653101216 & 32284255140318002679 & 32284255140318002679 & 32284255160971103895 & 32284255160971103895 \\
\hline 45 & 37223637886 & 37223637886 & 102625414714074250195 & 102625414714074250195 & 102625414751297888081 & 102625414751297888081 \\
\hline 46 & 66420162952 & 66420162952 & 326465312628541253282 & 326465312628541253282 & 326465312694961416234 & 326465312694961416234 \\
\hline 47 & 119740546576 & 119740546576 & 1039258352830707100287 & 1039258352830707100287 & 1039258352950447646863 & 1039258352950447646863 \\
\hline 48 & 213802390264 & 213802390264 & 3310561173602401804486 & 3310561173602401804486 & 3310561173816204194750 & 3310561173816204194750 \\
\hline 49 & 385525375648 & 385525375648 & 10552597199971538944446 & 10552597199971538944446 & 10552597200357064320094 & 10552597200357064320094 \\
\hline 50 & 688796847976 & 688796847976 & 33657783567745352117595 & $\begin{array}{l}33657783567745352117595 \\
\text { (omitted) }\end{array}$ & 33657783568434148965571 & 33657783568434148965571 \\
\hline
\end{tabular}

an each value of $B_{k}{ }^{(C)}, C_{k}, B_{k}$, and $C_{k}$, each enantiomeric pair is counted just once for chiral monosubstituted alkanes. 
By comparing eq. 9 and eq. 18, we obtain the following relationship:

$$
P(x)=x B(x) .
$$

This equation results in the equality between the coefficients of eq. $9\left(P_{k+1}\right)$ and those of eq. $18\left(B_{k}\right)$, i.e.,

$$
P_{k+1}=B_{k} .
$$

In fact, this relationship can be verified by comparing the $P_{k}$-column of Table 1 with the $B_{k}$-column of Table 4 .

Because eq. 19 for achiral primary monosubstituted alkanes is akin to eq. 44 , we are able to obtain the following equation:

$$
P_{k+1}^{(A)}=\alpha_{k}
$$

This relationship can be verified by comparing the $P_{k}^{(A)}$ column of Table 1 with the $\alpha_{k}$-column of Table 4 .

On the same line as eq. 44 , we obtain the following relationship by comparing eq. 10 and eq. 20 :

$$
P(x)^{(C)}=x C(x) .
$$

This equation results in the equality between the coefficients of eq. $9\left(P_{k+1}\right)$ and those of eq. $20\left(C_{k}\right)$, i.e.,

$$
P_{k+1}^{(C)}=C_{k} \text {. }
$$

This relationship can be verified by comparing the $P_{k}^{(C)}$ column of Table 1 with the $C_{k}$-column of Table 4 .

Chemically speaking, eq. 46 reflects the exclusive derivation of achiral primary monosubstituted alkanes from lower achiral alkyl ligands, e.g.,

$$
\bullet-\mathrm{R} \rightarrow \bullet-\mathrm{CH}_{2}-\mathrm{R} \text {. }
$$

On the other hand, eq. 47 reflects the exclusive derivation of chiral primary monosubstituted alkanes from lower chiral alkyl ligands, e.g.,

$$
\bullet-\mathrm{p}(\text { or } \bullet-\overline{\mathrm{p}}) \rightarrow \bullet-\mathrm{CH}_{2}-\mathrm{p}\left(\text { or } \bullet-\mathrm{CH}_{2}-\overline{\mathrm{p}}\right) \text {, }
$$

where each enantiomeric pair is counted just once. It follows that eq. 45 reflects the total derivation of primary monosubstituted alkanes from lower alkyl ligands.

\section{Enumeration of Monosubstituted Alkanes as Graphs}

To emphasize the difference between stereoisomers and graphs (constitutional isomers), let us count monosubstituted alkanes as graphs by using Pólya's theorem. Note that any CIs based on Pólya's theorem $[4,5]$ can be derived from the CI-CFs of Fujita's proligand method [1517] by omitting sphericities. In other words, Pólya's theorem lacks the sphericity concept. Although Pólya put it, "The cycle index knows many things." [10](page 67), the cycle index (CI) does not know the sphericities of cycles.
In connection with the present viewpoint of stereoisomer enumeration, it is important to know how Pólya's theorem lacks the sphericity concept.

Suppose that the number $\left(R_{k}\right)$ of monosubstituted alkanes of carbon content $k$ is itemized into those of primary $\left(P_{k}{ }^{(G)}\right)$, secondary $\left(S_{k}{ }^{(G)}\right)$, and tertiary ones $\left(T_{k}{ }^{(G)}\right)$, as shown in the following generating functions:

$$
\begin{aligned}
r(x) & =\sum_{k=0}^{\infty} R_{k} x^{k} \\
P(x)^{(G)} & =\sum_{k=0}^{\infty} P_{k}^{(G)} x^{k} \\
S(x)^{(G)} & =\sum_{k=1}^{\infty} S_{k}^{(G)} x^{k} \\
T(x)^{(G)} & =\sum_{k=1}^{\infty} T_{k}^{(G)} x^{k}
\end{aligned}
$$

where $x^{k}$ corresponds to the carbon content $k$ and we put $R_{0}=1, P_{(G)}=1, S_{0}{ }^{(G)}=0$ (omitted), and $T_{0}{ }^{(G)}=0$ (omitted).

Because any Pólya's CI can be regarded as a special case of the CI-CF of Fujita's proligand method with putting $r_{d}=a_{d}=c_{d}=b_{d}$, eq. 43 can be converted to the following functional equation by putting $r(x)=P(x)$ $+S(x)+T(x)$ in the left-hand side and $r(x)=b(x)=a(x)$ $=c(x)$ in the right-hand side and by adding 1 to assure recursive character:

$$
r(x)=1+\frac{x}{6}\left(r(x)^{3}+2 r\left(x^{3}\right)+3 r(x) r\left(x^{2}\right)\right) .
$$

Note that this equation gains recursive nature at the expense of the sphericity concept in contrast to eq. 43 .

Enumeration of primary monosubstituted alkanes as graphs is regarded as a special case of eq. 18. Hence, by putting $r(x)=a(x)=b(x)$, we obtain:

$$
P(x)^{(G)}=x r(x) \text {. }
$$

Similarly, enumeration of secondary monosubstituted alkanes as graphs can be conducted as a special case of eq. 28, where we put $r(x)=b(x)=c(x)$ as follows:

$$
S(x)^{(G)}=\frac{x}{2}\left((r(x)-1)^{2}+\left(r\left(x^{2}\right)-1\right)\right) .
$$

On a similar line, enumeration of tertiary monosubstituted alkanes as graphs is regarded as a special case of eq. 38. Hence, we obtain the following functional equation by putting $r(x)=a(x)=b(x)=c(x)$ :

$$
\begin{aligned}
T(x)^{(G)}= & \frac{x}{6}\left((r(x)-1)^{3}+2(r(x)-1)\right. \\
& \left.+3(r(x)-1)\left(r\left(x^{2}\right)-1\right)\right) .
\end{aligned}
$$

These generating functions were programmed by means of Maple programming language and the code stores in a file named "Graph1-100.mpl" tentatively. 
Table 5. Numbers of Monosubstituted Alkanes as Graphs

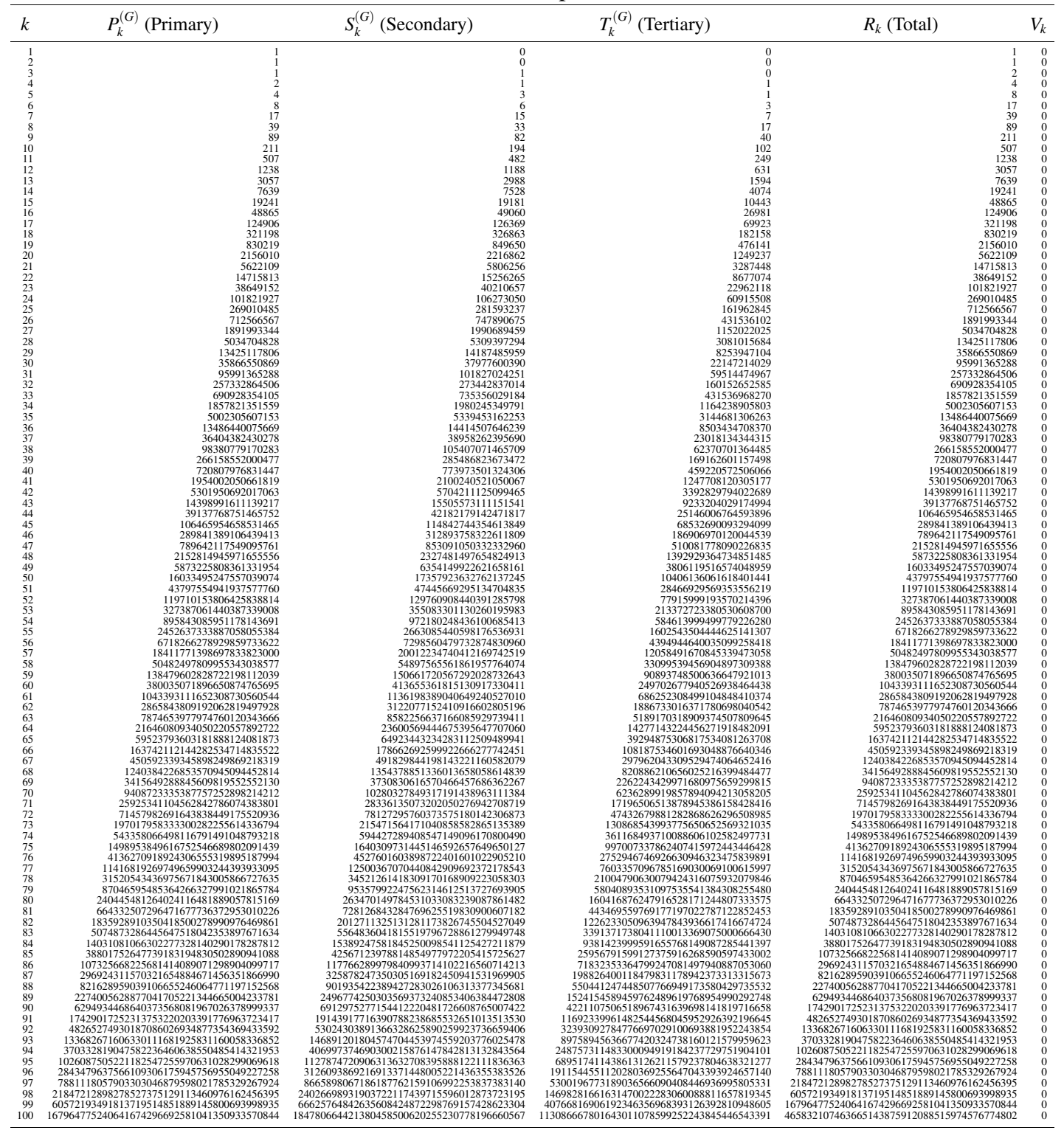

Maple program for enumeration monosubstituted alkanes, "Graph1-100.mpl":

"Definition of Functional Equation";

$r x:=1+(1 / 6) * x *\left(r 1^{\wedge} 3+2 * r 3+3 * r 1 * r 2\right)$;

"Initial Values";

$r 1:=1$;

r2:=1;

$r 3:=1 ;$

"Do Loop fo Calculation".

for ccntt from 1 to 100 by 1 do

centt :

$\mathrm{Rx}:=\operatorname{coeff}\left(r \mathrm{x}, \mathrm{x}^{\wedge} \operatorname{ccn} t \mathrm{t}\right):$

$r 1:=r 1+R x * x \wedge c$ cht $:$

$r 2:=r 2+R x^{*} x^{\wedge}(\operatorname{ccnt} t * 2):$

$r 3:=r 3+R x^{*} x^{\wedge}\left(\operatorname{ccn} t t^{*}\right):$

end do:

"Itemized Planted Trees";
Pg : $=x^{*} r 1:$

$\mathrm{Sg}:=(1 / 2){ }^{*} \mathrm{X}\left((r 1-1)^{\wedge} 2+(r 2-1)\right):$

$\mathrm{Tg}:=(1 / 6) * \mathrm{X} *\left((r 1-1)^{\wedge} 3+2 *(r 3-1)\right.$

$+3 *(r 1-1) *(r 2-1)):$

$\mathrm{RR}:=\mathrm{Pg}+\mathrm{Sg}+\mathrm{Tg}:$

"Validity Test";

$\mathrm{V}:=r \mathrm{X}-\mathrm{RR}$ :

"Print-Out of Results" ;

for centt from 1 to 100 by 1 do

printf $(" \circ d \& \% d \& \% d \& \% d$

$\& \% d \& \div d \backslash \backslash \backslash \backslash \backslash n "$,

centt,

coeff (Pg, $x^{\wedge}$ ccntt),

coeff (Sg, $x^{\wedge}$ ccntt),

coeff $\left(\mathrm{Tg}, \mathrm{x}^{\wedge} \mathrm{ccnt} t\right)$,

coeff (rx, $x^{\wedge}$ ccntt),

coeff $\left.\left(V, x^{\wedge} \operatorname{ccnt} t\right)\right)$;

end do; 
In this code, we use the following symbols: $r x$ for $r(x)$ (eq. 53), $\mathrm{Pg}$ for $P(x)^{(G)}$ (eq. 54), $\mathrm{Sg}$ for $S(x)^{(G)}$ (eq. 55, and $\mathrm{Tg}$ for $T(x)^{(G)}$ (eq. 56); as well as $r 1$ for $r(x)$, , 2 for $r\left(x^{2}\right)$, and $r 3$ for $r\left(x^{3}\right)$. The paragraph "Validity Test" confirms that the values by the recursive calculation ( $r \mathrm{x}$ for $r(x)$ ) are equal to the sum of the itemized values (RR or $\left.P(x)^{(G)}+S(x)^{(G)}+T(x)^{(G)}\right)$. This is directly confirmed by summing up the functional equations:

$$
\begin{aligned}
& P(x)^{(G)}+S(x)^{(G)}+T(x)^{(G)} \\
& \quad=\frac{x}{6}\left(r(x)^{3}+2 r\left(x^{3}\right)+3 r(x) r\left(x^{2}\right)\right),
\end{aligned}
$$

which is identical with $r(x)$ (eq. 53) except for the initial value 1 added for recursion.

The results are summarized in Table 5, where the coefficients appear in the $P_{k}{ }^{(G)}$ - (primary), the $S_{k}^{(G)}$ - (secondary), the $T_{k}^{(G)}$ - (tertiary), and the $R_{k}$-columns, respectively. The last column $V_{k}$ contains zero values for indicating the validity of the present calculation.

The results up to 20 shown in Table 5 are identical with those of Henze and Blair [1], the results from carbon content 21 to 30 are identical with those of Perry [23], and the results from carbon content up to 50 are identical with those collected in Trinajstić's book [24](pages 153-154 of Vol. II).

According to eq. 54, we obtain the following relationship:

$$
P_{k+1}^{(G)}=R_{k}
$$

The relationship can be verified by comparing the $P_{k}{ }^{(G)}$ column of Table 5 with the $R_{k}$-column of the same table. Obviously, this is a graph-counting counterpart of eq. 45 . Chemically speaking, eq. 58 reflects the exclusive derivation of primary monosubstituted alkanes (as graphs) from lower alkyl ligands (as graphs).

\section{Discussions}

\subsection{Pseudoasymmetric Cases}

Among the enumeration results collected in Tables 1-3, the $S_{k}{ }^{(A)}$-column in Table 2 exhibits a special feature to be pointed out. Thus, we can find that each value of $S_{k}{ }^{(A)}$ (Table 2) vanishes to zero when the carbon content $k$ is even. This feature holds true in general. In order to be achiral, a secondary monosubstituted alkane should have a formula represented by $\mathrm{X}-\mathrm{CHR}_{2}$ or $\mathrm{X}-\mathrm{CHp} \overline{\mathrm{p}}$ where the $\mathrm{R}$ is an achiral ligand or the pair $\mathrm{p} / \overline{\mathrm{p}}$ represents a pair of enantiomeric ligands. As a result, the total carbon content $(k)$ is calculated to be odd because the number represented by $2 \ell+1(=k)$ means an odd number whether the carbon content $(\ell$ ) of the $\mathrm{R}$ (or $\mathrm{p}$ ) is odd or even. Hence, there exists no achiral secondary monosubstituted alkane with an even $k$ (i.e., $S_{k}{ }^{(A)}=0$ if $k$ is even). In other words, all of the secondary monosubstituted alkanes characterized by even carbon contents $(k)$ are chiral and contribute to $S_{k}{ }^{(C)}$ ( $k$ : even).

Achiral secondary monosubstituted alkanes having the general formula $\mathrm{X}-\mathrm{CHp} \overline{\mathrm{p}}$ are recognized as pseudoasymmetric cases. The two diastereomers corresponding to each formula $\mathrm{X}-\mathrm{CHp} \overline{\mathrm{p}}$ with carbon content $k$ contribute by two to the value of $S_{k}^{(A)}$ (Table 2).<smiles>[X]C(CCCC)CCCC</smiles><smiles>[X]C([C@@H](C)CC)[C@H](C)CC</smiles>
4<smiles>[X]C(CC(C)C)CC(C)C</smiles>
7<smiles>[X]C([C@@H](C)CC)[C@H](C)CC</smiles><smiles>[X]C(C(C)(C)C)C(C)(C)C</smiles>

Figure 4. Achiral secondary monosubstituted alkanes of carbon content 9. If necessary, configurations are shown by wedged bonds and/or hashed dash bonds.

For example, let us examine the case of $S_{9}{ }^{(A)}=5$ in Table 2. The five achiral monosubstituted alkanes are listed in Figure 4. Among them, 5 and $\mathbf{6}$ are diastereomeric and show pseudoasymmetric nature. The remaining monosubstituted alkanes $\mathbf{4}, \mathbf{7}$, and $\mathbf{8}$ are obviously represented by the general formula $\mathrm{X}-\mathrm{CHR} \mathrm{R}_{2}$, where the $\mathrm{R}$ represents an achiral butyl ligand. It should be noted that Figure 4 contains all types of butyl substituents, i.e., n-butyl (for 4), sec-butyl (for 5 and 6), iso-butyl (for 7), and $t$-butyl (for 8). These butyls in turn are enumerated as $P_{4}{ }^{(A)}=2$ (Table 1$), S_{4}{ }^{(C)}=1$ (Table 2), and $T_{4}{ }^{(A)}=$ 1 (Table 3$)$. Note that the numbers of such alkyl ligands are equal to the numbers of the corresponding monosubstituted alkanes.

The last finding in the preceding paragraph can be extended into general cases. When achiral secondary monosubstituted alkanes of carbon content $k$ are represented by the formula $\mathrm{X}-\mathrm{CHR}_{2}$ or $\mathrm{X}-\mathrm{CHp} \overline{\mathrm{p}}$, they are composed of two R's of carbon content $(k-1) / 2$ or of a pair of $\mathrm{p}$ and $\overline{\mathrm{p}}$ of carbon content $(k-1) / 2$. The two R's and the pair of $\mathrm{p}$ and $\overline{\mathrm{p}}$ cover all of alkyl ligands of carbon content $(k-$ $1) / 2$. 


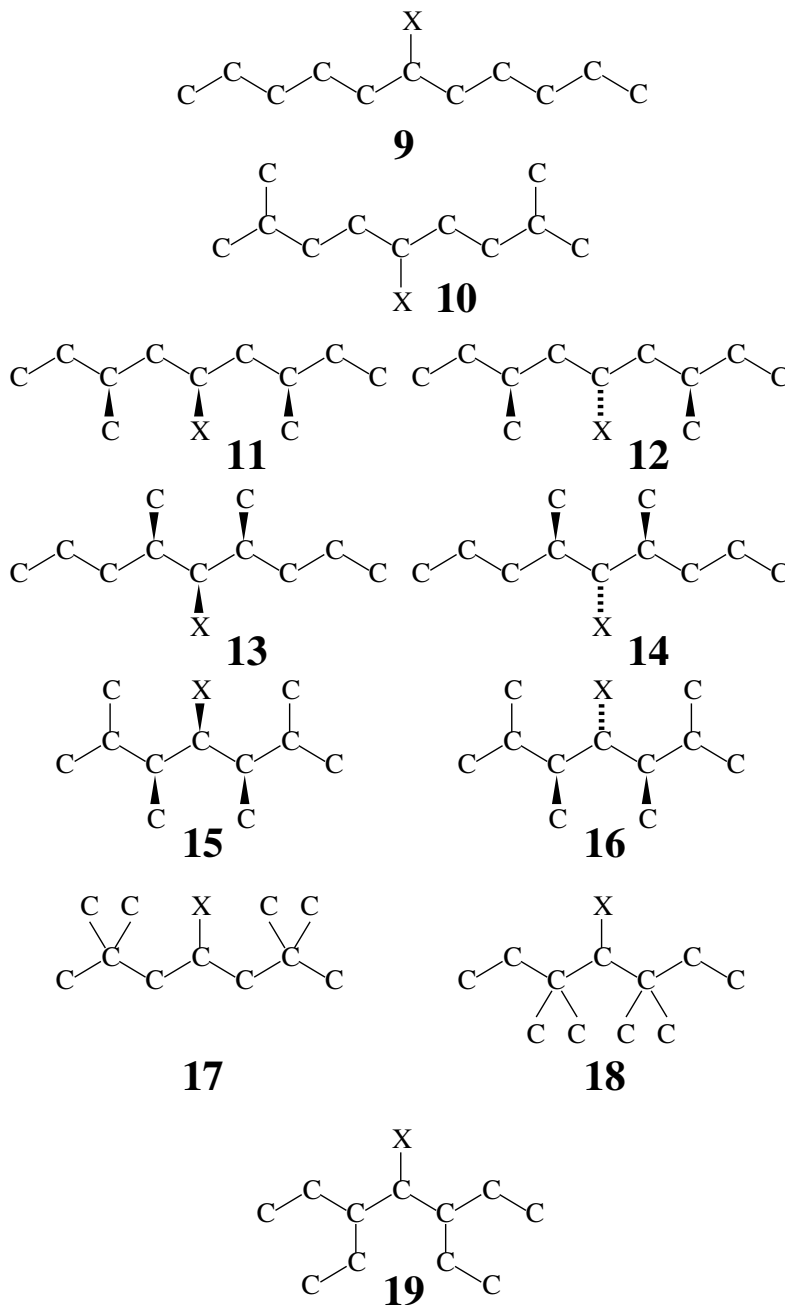

Figure 5. Achiral secondary monosubstituted alkanes of carbon content 11 . If necessary, configurations are shown by wedged bonds and/or hashed dash bonds.

To exemplify a more complicated case, let us examine the case of $S_{11}{ }^{(A)}=11$ in Table 2 . Because of the relationship $(11-1) / 2=5$, we should take alkyl ligands of carbon content 5 into account. Thus, there are 8 alkyl ligands of carbon content 5 , where we find $P_{5}{ }^{(A)}=3$ (for pentyl, 3methylbut-1-yl, and 2,2-dimethylprop-1-yl) and $P_{5}{ }^{(C)}=1$ (for 2-methylbut-1-yl) in Table 1; $S_{5}{ }^{(A)}=1$ (for pent-3-yl) and $S_{5}{ }^{(C)}=2$ (for 1-methylbut-1-yl and 3-methylbut-2-yl) in Table 2; as well as $T_{5}{ }^{(A)}=1$ (for $t$-pentyl) and $T_{5}{ }^{(C)}=$ 0 in Table 3. Because each enantiomeric pair of chiral ligands $\left(P_{5}{ }^{(C)}, S_{5}{ }^{(C)}\right.$, and $\left.T_{5}{ }^{(C)}\right)$ generates two diastereomers of pseudoasymmetric nature, there should appear 11 achiral secondary monosubstituted alkanes, where we calculate $P_{5}{ }^{(A)}+2 P_{5}{ }^{(C)}+S_{5}{ }^{(A)}+2 S_{5}{ }^{(C)}+T_{5}{ }^{(A)}+2 T_{5}{ }^{(C)}$ $=3+1 \times 2+1+2 \times 2+1+0=11$.

The 11 achiral monosubstituted alkanes of carbon content 11 are listed in Figure 5. Among them, three pairs, i.e., 11/12 (from 2-methylbut-1-yl), 13/14 (from 1- methylbut-1-yl), and 15/16 (from 3-methylbut-2-yl) are produced from pairs of chiral pentyl ligands according to the general formula $\mathrm{X}-\mathrm{CHp} \overline{\mathrm{p}}$, where the two stereoisomers of each pair are diastereomeric and show pseudoasymmetric nature. The remaining 5 monosubstituted alkanes are obviously represented by the general formula $\mathrm{X}-\mathrm{CHR}_{2}$, where the $\mathrm{R}$ represents an achiral pentyl ligand.

\subsection{Stereoisomers vs. Graphs}

To show the effect of itemization due to the degree of branching, let us depict monosubstituted alkanes of carbon content 7 .

The $k=7$ row of Table 1 shows that there are 8 achiral primary monosubstituted alkanes and 10 enantiomeric pairs of chiral ones. They are listed in Figure 6, where either one enantiomer is depicted as a representative of each pair of enantiomers.

Because the 8 achiral primary monosubstituted alkanes (20-27) are different from each other as graphs, they are constitutional isomers, which are counted so as to be 8 constitutional isomers (graphs).

As found easily, they are represented by $\mathrm{X}-\mathrm{CH}_{2}-$ $\mathrm{R}$, where the $\mathrm{R}$ covers all of the achiral hexyl ligands. In agreement with eq. 46 , the presence of the 8 achiral primary monosubstituted alkanes of carbon content 7 (i.e., 20-27) is related to the value $\alpha_{6}=8$ in Table 4 .

In agreement with eq. 48 , the presence of 10 chiral primary monosubstituted alkanes of carbon content 7 $\left(P_{7}{ }^{(C)}=10\right.$ in Table 1) is related to the value $C_{6}=10$ in Table 4. Note that they are represented by $\mathrm{X}-\mathrm{CH}_{2}-\mathrm{p}$ (or $\mathrm{X}-\mathrm{CH}_{2}-\overline{\mathrm{p}}$ ), where the $\mathrm{p}$ (or $\overline{\mathrm{p}}$ ) covers all the chiral hexyl ligands.

Among the 10 chiral primary monosubstituted alkanes (28-37), there appears one diastereomeric case, i.e., $\mathbf{3 2}$ and $\mathbf{3 3}$, which are identical with each other as graphs. The set of $\mathbf{3 2}$ and $\mathbf{3 3}$ is regarded as a single constitutional isomer, which is counted just once, if we rely on Pólya's theorem. It follows that the 10 primary monosubstituted alkanes (28-37) are counted so as to be 9 constitutional isomers (graphs).

As a result, there are 17 constitutional isomers for primary monosubstituted alkanes $(8+9=17)$. The number appears as $P_{7}{ }^{(G)}$ in Table 5, which is obtained by means of the enumeration based on Pólya's theorem.

Because of eq. 58, the number of hexyl ligands as graphs is evaluated to be $R_{6}=17$, as shown in Table 5 . Hence we can confirm the relationship, $P_{7}{ }^{(G)}=R_{6}=17$, in agreement with eq. 58 .

The $k=7$ row of Table 3 shows that there are 2 achiral secondary monosubstituted alkanes and 17 enantiomeric pairs of chiral ones. They are listed in Figure 7, where either one enantiomer is depicted as a representative of each pair of enantiomers. 
Achiral primary monosubstituted alkanes<smiles>[X]CCCCCCC</smiles><smiles>[Y]CCCCC(C)C</smiles>

20<smiles>[Y]CC(C)(C)CCC</smiles>

22<smiles>[X]CCC(C)(C)CC</smiles><smiles>[X]CC(C)(CC)CC</smiles>

24<smiles>[X]CCC(CC)CC</smiles>
26

\section{1}<smiles>[X]CCCC(C)(C)C</smiles>

23

25<smiles>[X]CC(C)(C)C(C)C</smiles>

27

Chiral primary monosubstituted alkanes<smiles>[X]CC(C)CCCC</smiles><smiles>[X]CCC(C)CCC</smiles><smiles>[X]CCCC(C)CC</smiles><smiles>[X]CC(CC)C([AlH2])CC</smiles><smiles>[X]CC(C)C(C)CC</smiles><smiles>[X]CC(C)C(C)CC</smiles><smiles>[X]CCC(C)C(C)C</smiles><smiles>CCC(CC)C(C)C</smiles><smiles>[X]CC(C)CC(C)C</smiles><smiles>[X]CC(C)C(C)(C)C</smiles>

Figure 6. Primary monosubstituted alkanes of carbon content 7 . Configurations are shown by wedged bonds and/or hashed dash bonds, if necessary. An arbitrary enantiomer is depicted for a representative of each pair of enantiomers.

Achiral secondary monosubstituted alkanes<smiles>[Y]C(CCC)CCC</smiles>

38<smiles>[Y]C(C(C)C)C(C)C</smiles>

Chiral secondary monosubstituted alkanes<smiles>CCCCCC(C)I</smiles>

40<smiles>[Y]C(CCC)C(C)C</smiles>

42<smiles>CCCCC(C)CC</smiles>
41 '<smiles>[Y]C(CC)CC(C)C</smiles>

43<smiles>[Y]C(C)CCC(C)C</smiles><smiles>[Y]C(C)C(C)C([AsH3])CC</smiles><smiles>[Y]C(C)C(C)C([13CH3])CC</smiles><smiles>[Y8]C(CC)[C@H](C)CC</smiles><smiles>[Y]C(C)CC(C)CC</smiles>

49<smiles>CCC([AlH2])C(C)(C)C</smiles>

50<smiles>[Y]C(C)CC(C)(C)C</smiles>

52<smiles>[Y]C(C)C(C)(C)CC</smiles><smiles>[Y]C(C)C(C)C(C)C</smiles><smiles>[Y]C(C)C(C)C(C)C</smiles><smiles>[Y]C(C)C(CC)CC</smiles>

Figure 7. Secondary monosubstituted alkanes of carbon content 7. Configurations are shown by wedged bonds and/or hashed dash bonds, if necessary. An arbitrary enantiomer is depicted for a representative of each pair of enantiomers. 
Achiral tertiary monosubstituted alkanes<smiles>[X]C(C)(C)CCCC</smiles><smiles>[Y]S(=O)(=O)C(CC)(CC)CC</smiles><smiles>[X]C([X])(C)CC(C)C</smiles>

59

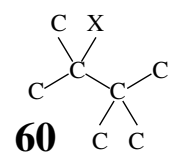

Chiral tertiary monosubstituted alkanes<smiles>[Y]C(C)(CC)CCC</smiles>

61<smiles>[X]C(C)(C)C(C)CC</smiles><smiles>[X]C(C)(CC)C(C)C</smiles>

Figure 8. Tertiary monosubstituted alkanes of carbon content 7 . Configurations are shown by wedged bonds and/or hashed dash bonds, if necessary. An arbitrary enantiomer is depicted for a representative of each pair of enantiomers.

The 2 achiral secondary monosubstituted alkanes (38 and 39) are different from each other as graphs so that there are 2 constitutional isomers.

Among the 17 chiral secondary monosubstituted alkanes (40-56), there appear four sets of diastereomers, i.e., 45/46, 47/48, 49/50, and 54/55, each of which is regarded as a single constitutional isomer. Hence, the 17 chiral secondary monosubstituted alkanes (40-56) are counted so as to be 13 constitutional isomers.

It follows that there are 15 constitutional isomers for secondary monosubstituted alkanes $(2+13=15)$. The number appears as $S_{7}{ }^{(G)}$ in Table 5, which is obtained by means of the enumeration based on Pólya's theorem.

According to the $k=7$ row of Table 3 , there are 4 achiral tertiary monosubstituted alkanes and 3 enantiomeric pairs of chiral ones. They are listed in Figure 8, where either one enantiomer is depicted as a representative of each pair of enantiomers.

The 4 achiral tertiary monosubstituted alkanes (5760) are constitutional isomers and the 3 chiral tertiary monosubstituted alkanes (61-63) are constitutional isomers. Hence, there are 7 constitutional isomers for tertiary monosubstituted alkanes. The number appears as $T_{7}^{(G)}$ in Table 3, which is obtained by means of the enumeration based on Pólya's theorem.

Consequently, we obtain $17+15+7=39$ for the total number of constitutional isomers of monosubstituted alkanes, which appears as $R_{7}$ in Table 5 .

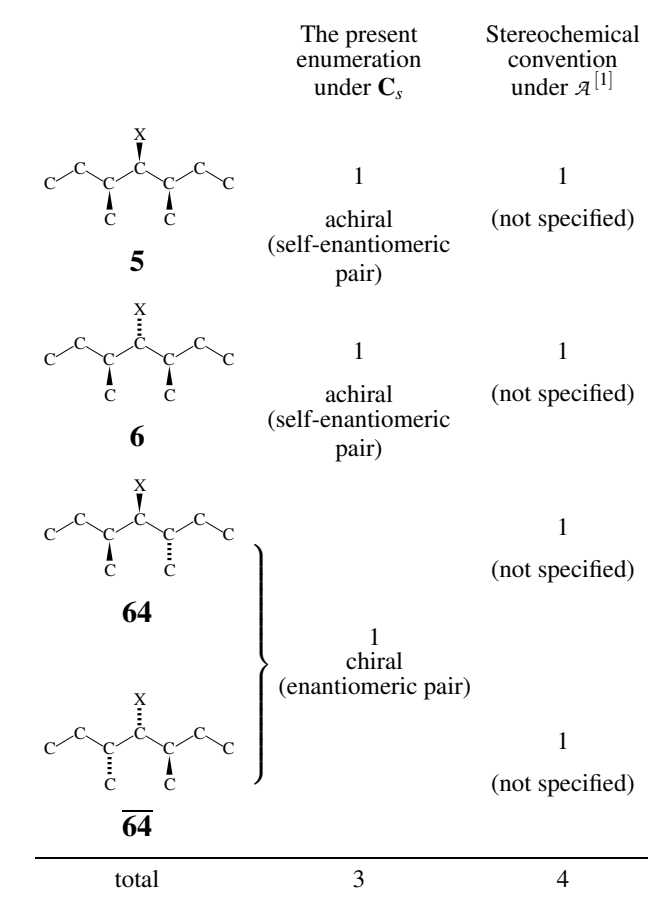

Figure 9. Equivalence classes for secondary monosubstituted alkanes of carbon content 9. Pseudoasymmetric cases and a related pair of enantiomers.

\subsection{Selection of Equivalence Classes}

According to a stereochemical convention, two enantiomers of each pair are counted separately so as to contribute enumeration values by 2 . In contrast, the present methodology adopts the criterion that each pair of enantiomers is counted just once so as to contribute enumeration values by 1 . It is worthwhile to discuss the effect of the present criterion in comparison with the former criterion of the stereochemical convention.

The difference between the two criteria stems from the selection of equivalence classes, which depends on the selection of groups as bases of respective enumeration procedures. The difference is exemplified by using pseudoasymmetric and related cases, as shown in Figure 9.

The stereochemical convention counts $5,6,64$, and $\overline{\mathbf{6 4}}$ separately so as to give isomer number 4 , as shown in Figure 9. This enumeration result implies the use of the alternating group of degree $1\left(\mathcal{A}^{[1]}\right)$, which is isomorphic to $\mathbf{C}_{1}$ in the present approach. To illustrate what happens under the stereochemical convention, let us adopt the CI$\mathrm{CF}$ for $\mathbf{C}_{1}$ (eq. 22), where we use the following ligand inventory:

$$
b_{d}=\mathrm{p}^{d}+\overline{\mathrm{p}}^{d}=x^{4 d}+\bar{x}^{4 d}=2 x^{4 d}
$$

in accord with the substitution of enantiomeric sec-butyl ligands $\mathrm{p}=x^{4}$ and $\overline{\mathrm{p}}=\bar{x}^{4}=x^{4}$ ). Note that the symbol $\bar{x}$ represents the enantiomer of $x$, but is equal to $x$ if carbon content is considered. By introducing eq. 59 into 
the right-hand side of eq. 22 and by multiplying $x$ for the central carbon atom, we obtain the following generating functions:

$$
x b_{1}^{2}=x(\mathrm{p}+\overline{\mathrm{p}})^{2}=x\left(x^{4}+\bar{x}^{4}\right)^{2}=4 x^{9},
$$

where the coefficient 4 of the term $x^{9}$ indicates the presence of 4 isomers of carbon content 9 under the criterion provided by $\mathbf{C}_{1}$ (or equivalently $\mathcal{A}^{[1]}$ ). This result is in agreement with the stereochemical convention, where the four compounds $\mathbf{5}, \mathbf{6}, \mathbf{6 4}$, and $\overline{\mathbf{6 4}}$ are counted separately. In other words, each of the compounds counted (i.e., 5, 6, $\mathbf{6 4}$, and $\overline{\mathbf{6 4}}$ ) is independently regarded as an equivalence class due to $\mathbf{C}_{1}\left(\mathcal{A}^{[1]}\right)$.

The enumeration result described in the preceding paragraph reveals implications concealed in the stereochemical convention:

1. The independent behavior under the action of $\mathbf{C}_{1}\left(\mathcal{A}^{[1]}\right)$ means that each compound is recognized to be "chiral" in spite of its realistic chirality/achirality, because the action of $\mathbf{C}_{1}\left(\mathcal{A}^{[1]}\right)$ contains no reflection operations. If the expression "chiral" used in characterizing the achiral compounds (5 and 6) seems to be rather strange, we can safely say that the compounds have no information on their chirality/achirality, as shown by the note "not specified" in Figure 9. Hence, the recognition of chirality/achirality is left afterward in the hands of stereochemists, who subsequently apply reflection operations to each compound for the purpose of symmetry characterization.

2. Moreover, the enumeration under the action of $\mathbf{C}_{1}$ (or equivalently $\mathcal{A}^{[1]}$ ) specifies no relationships among the four compounds, 5, 6, 64, and $\overline{\mathbf{6 4}}$. In particular, the enantiomeric relationship between $\mathbf{6 4}$ and $\overline{\mathbf{6 4}}$ cannot be specified under the action of $\mathbf{C}_{1}$ (or equivalently $\mathcal{A}^{[1]}$ ), because the $\mathbf{C}_{1}$ contains no reflection operations. Hence, the specification of enantiomeric relationships is regarded as a subsequent and distinct step using reflection operations. This step of symmetry characterization requires a manual examination by intelligence of stereochemists.

The implications itemized above reveal that the number 4 for counting $5, \mathbf{6}, \mathbf{6 4}$, and $\overline{\mathbf{6 4}}$ has been obtained at the expense of symmetry characterizations, i.e., the recognition of chirality/achirality and the specification of enantiomeric relationships. In other words, there is a logical gap between the first step using $\mathbf{C}_{1}$ or $\mathcal{A}^{[1]}$ (the enumeration step) and the second step using reflection operations (the step of symmetry characterization). The logical gap has been frequently overlooked by organic stereochemists, because they can easily and unconsciously skip the logical gap by their intuition.
In contrast, the present approach has attempted to fill the logical gap explicitly by using the point group $\mathbf{C}_{s}$, as shown in Figure 2. It should be emphasized that an equivalence class under the action of $\mathbf{C}_{s}$ is composed of an achiral compound (as a self-enantiomeric pair) or of a pair of enantiomers. Thus, chiral compounds are counted once per pair of enantiomers.

By following Fujita's proligand method [15-17], we use the following ligand inventories:

$$
\begin{aligned}
& b_{d}=\mathrm{p}^{d}+\overline{\mathrm{p}}^{d}=x^{4 d}+\bar{x}^{4 d}=2 x^{4 d} \\
& c_{d}=2 \mathrm{p}^{d / 2} \overline{\mathrm{p}}^{d / 2}=2 x^{2 d} \bar{x}^{2 d}=2 x^{4 d},
\end{aligned}
$$

where we select enantiomeric sec-butyl ligands as substituents $\left(\mathrm{p}=x^{4}\right.$ and $\left.\overline{\mathrm{p}}=x^{4}\right)$. These inventories are introduced into the CI-CF shown in eq. 21 and multiplied by $x$ to give the following generating function:

$$
\begin{aligned}
& \frac{x}{2}\left(b_{1}^{2}+c_{2}\right) \\
& =\frac{x}{2}\left\{(\mathrm{p}+\overline{\mathrm{p}})^{2}+2 \mathrm{p} \overline{\mathrm{p}}\right\} \\
& =\frac{x}{2}\left\{\left(x^{4}+\bar{x}^{4}\right)^{2}+2 x^{4} \bar{x}^{4}\right\}=3 x^{9} .
\end{aligned}
$$

The coefficient 3 of the term $x^{9}$ indicates the presence of three compounds counted per pair of enantiomers, which are 5 (an achiral compound as a self-enantiomeric pair), $\mathbf{6}$ (an achiral compound as a self-enantiomeric pair), and $\mathbf{6 4} / \overline{\mathbf{6 4}}$ (an enantiomeric pair of two chiral compounds), as shown in Figure 6.

To count achiral compounds, the inventory (eq. 62) is introduced into the $\mathrm{CI}-\mathrm{CF}_{A}$ shown in eq. 23 and multiplied by $x$ to give the following generating function:

$$
x c_{2}=x\left(2 x^{4} \bar{x}^{4}\right)=2 x^{9} .
$$

The coefficient 2 of the term $x^{9}$ indicates the presence of two achiral compounds counted per pair of enantiomers. They are $\mathbf{5}$ and $\mathbf{6}$, each of which is an achiral compound regarded as being a self-enantiomeric pair (Figure 6).

After the inventories (eqs. 61 and 62) are introduced into the CI-CF ${ }_{C}$ shown in eq. 24 and $x$ is multiplied, the resulting equation is expanded to give the following generating function:

$$
\begin{aligned}
& \frac{x}{2}\left(b_{1}^{2}-c_{2}\right) \\
& \quad=\frac{x}{2}\left\{(\mathrm{p}+\overline{\mathrm{p}})^{2}-2 \mathrm{p} \overline{\mathrm{p}}\right\} \\
& \quad=\frac{x}{2}\left\{\left(x^{4}+\bar{x}^{4}\right)^{2}-2 x^{4} \bar{x}^{4}\right\}=x^{9} .
\end{aligned}
$$

The coefficient 1 of the term $x^{9}$ indicates the presence of one pair of enantiomers, which is represented by the pair $\mathbf{6 4} \overline{\mathbf{6 4}}$, as shown in Figure 6.

Moreover, eq. 22, which has been used to obtain eq. 60 is also involved in the present approach because the $\mathbf{C}_{1}$ is a subgroup of the $\mathbf{C}_{s}$. Obviously, the combination of eqs. 63-65 together with eq. 60 is more informative than the stereochemical convention using eq. 60 only. 
From the viewpoint of the present approach, the values collected in the $P_{k}^{(A)}-, P_{k}^{(C)}$-, and $P_{k}$-columns of Table 1 are concerned with equivalence classes due to $\mathbf{C}_{s}$, because they are based on the $\mathbf{C}_{s}$-skeleton shown in Figure 1 . The three columns contain consistent values under the action of $\mathbf{C}_{s}$. This situation holds true for the columns contained in Tables 2 and 3.

In place of the present column constitutions of Tables 1-3, we can select, for example, a column listing the values of $P_{k}{ }^{(A)}$, a column listing the values of $2 P_{k}{ }^{(C)}$, and a column listing the values of $P_{k}^{(A)}+2 P_{k}{ }^{(C)}$ in agreement with the stereochemical convention. As a result of this type of column constitution, we find that the column listing the values of $P_{k}{ }^{(A)}$ is based on $\mathbf{C}_{s}$, while the column listing the values of $2 P_{k}{ }^{(C)}$ and the column listing the values of $P_{k}^{(A)}+2 P_{k}{ }^{(C)}$ are based on $\mathbf{C}_{1}$. Hence, this type of column constitution is inconsistent from the viewpoint of point-group theory.

\section{Conclusions}

Primary, secondary, and tertiary monosubstituted alkanes are counted as stereoisomers by means of Fujita's proligand method [15-17]. According to cycle indices with chirality fittingness (CI-CFs), three kinds of sphericity indices (SIs), i.e., $a_{d}$ for homospheric cycles, $\mathrm{c}_{d}$ for enantiospheric cycles, and $\mathrm{b}_{d}$ for hemispheric cycles, are replaced by $a\left(x^{\mathrm{d}}\right), c\left(x^{\mathrm{d}}\right)$, and $b\left(x^{\mathrm{d}}\right)$ so as to produce functional equations for recursive calculation. After the derivation of respective functional equations for counting primary, secondary, and tertiary monosubstituted alkanes, they are programmed by means of the Maple programming language and executed to obtain values up to carbon content 100. The respective results are collected in a tabular form, where the numbers of stereoisomers are further itemized into achiral and chiral ones. By omitting the sphericity concept, such CI-CFs are transformed into Pólya's cycle indices (CIs), which are applied to the enumeration of primary, secondary, and tertiary monosubstituted alkanes as graphs (chemically, constitutional isomers). The results of Fujita's proligand method are compared with those based on Pólya's theorem in connection with several cases of pseudoasymmetry.

We gratefully acknowledge the financial support given to our recent project by the Japan Society for the Promotion of Science: Grant-in-Aid for Scientific Research B (No. 18300033, 2006).

\section{References}

[1] H. R. Henze and C. M. Blair, J. Am. Chem. Soc., 53, 3042 (1931)
[2] A. Cayley, Philos. Mag., 47, 444-446 (1874).

[3] A. Cayley, Rep. Brit. Assoc. Advance. Sci., 45, $257-$ 305 (1875).

[4] G. Pólya, Acta Math., 68, 145-254 (1937).

[5] G. Pólya and R. C. Read, Combinatorial Enumeration of Groups, Graphs, and Chemical Compounds, Springer-Verlag, New York (1987).

[6] H. Hosoya, Kagaku no Ryoiki, 26, 21-33 (1972).

[7] D. H. Rouvray, Chem. Soc. Rev., 3, 355-372 (1974).

[8] O. E. Polansky, MATCH Commun. Math. Comput. Chem., 1, 11- 31 (1975).

[9] A. T. Balaban, ed., Chemical Applications of Graph Theory, Academic Press, London (1976).

[10] G. Pólya, R. E. Tarjan, and D. R. Woods, Notes on Introductory Combinatorics, Birkhäuser, Boston (1983).

[11] K. Balasubramanian, Chem. Rev., 85, 599-618 (1985).

[12] R. W. Robinson, F. Harary, and A. T. Balaban, Tetrahedron, 32, 355-361 (1976).

[13] S. Fujita, J. Am. Chem. Soc., 112, 3390-3397 (1990).

[14] S. Fujita, Symmetry and Combinatorial Enumeration in Chemistry, Springer-Verlag, BerlinHeidelberg (1991).

[15] S. Fujita, Theor. Chem. Acc., 113, 73-79 (2005).

[16] S. Fujita, Theor. Chem. Acc., 113, 80-86 (2005).

[17] S. Fujita, Theor. Chem. Acc., 115, 37-53 (2006).

[18] S. Fujita, Theor. Chem. Acta, 91, 315-332 (1995).

[19] S. Fujita, Theor. Chem. Acc., 99, 224-230 (1998).

[20] S. Fujita, Bull. Chem. Soc. Jpn., 71, 1587-1596 (1998).

[21] S. Fujita, Theor. Chem. Acc. (2006), in press.

[22] M. B. Monagan, K. O. Geddes, H. M. Heal, G. Labahn, S. M. Vorkoetter, J. McCarron, and D. DeMarco, Maple 9. Introductory Programming Guide, Maplesoft, Waterloo (2006).

[23] D. Perry, J. Am. Chem. Soc., 54, 2918-2920 (1932).

[24] N. Trinajstić, Chemical Graph Theory, Vol. I and II, CRC, Boca Raton (1983). 